\title{
LA PANOPLIA IBÉRICA DE GUERRA RECUPERADA EN LA TORRE T3 DEL POBLADO PROTOHISTÓRICO DE L'ASSUT (TIVENYS, BAIX EBRE, TARRAGONA)
}

\author{
THE IBERIAN PANOPLY OF WAR RECOVERED FROM TOWER T3 OF THE PROTOHISTORIC \\ SETTLEMENT OF L'ASSUT (TIVENYS, BAIX EBRE, TARRAGONA)
}

POR

\author{
Jordi Diloli Fons ${ }^{*}$, Ramon Ferré Anguix ${ }^{* *}$ y Marc Fontanet Fontanet ${ }^{* * *}$
}

\section{RESUMEN - AbSTRACT}

En el artículo presentamos el estudio de un conjunto armamentístico de época ibérica recuperado durante las intervenciones arqueológicas efectuadas en el poblado de L'Assut (Tivenys, Baix Ebre, Tarragona), concretamente en el interior de la torre T3, un edificio arrasado violentamente entre finales del siglo III e inicios del II ANE. La panoplia está compuesta por una lanza, una falárica, un soliferreum, un cuchillo afalcatado y al menos un fragmento identificable de la vaina de una espada tipo La Tène, entre otros objetos. Se trata de un hallazgo excepcional en el nordeste peninsular, tanto por haberse localizado en un espacio de hábitat, como por sus características y cronología.

In this article, we present the study of an arms ensemble from the Iberian period which was recovered from the archaeological excavations in L'Assut settlement (Tivenys, Baix Ebre, Tarragona). Specifically, they are from inside of the tower T3, which is a building that was violently demolished between the end of the 3rd century and the beginning of the 2 nd BCE. The arms collection consists of a spear, a falarica, a soliferreum, a curved knife and at least one identifiable fragment of a sword sheath similar to La Tène, among other objects. It is an exceptional discover in the Northeast of the Peninsula, not only because it was located in an inhabited place, but also for its characteristics and chronology.

\section{Palabras Clave - Keywords}

L'Assut; Protohistoria; iberos; armas; noreste peninsular.

L'Assut; Proto-history; Iberian; arms; north-eastern Iberian peninsula.

\footnotetext{
* Grup de Recerca Seminari de Protohistòria i Arqueologia (GRESEPIA), Universitat Rovira i Virgili (URV), jordi.diloli@urv.cat / ORCID iD: https://orcid.org/0000-0001-5048-9308 / Institut Català d'Arqueologia Clàssica (ICAC). Plaça d'en Rovellat, s/n · 43003 Tarragona.

** Grup de Recerca Seminari de Protohistòria i Arqueologia (GRESEPIA), Universitat Rovira i Virgili (URV), ramon.ferre@urv.cat / ORCID iD: https://orcid.org/0000-0002-8840-2682 / Institut Català d'Arqueologia Clàssica (ICAC). Plaça d'en Rovellat, s/n · 43003 Tarragona.

${ }^{* * * *}$ Grup de Recerca Seminari de Protohistòria i Arqueologia (GRESEPIA), Universitat Rovira i Virgili (URV), marc.fontanet@estudiants.urv.cat / ORCID iD: https://orcid.org/0000-0003-3989-9116
} 


\section{Cómo CitAR ESTE ARTículo / Citation}

Diloli Fons, J.; Ferré Anguix, R. y Fontanet Fontanet, M. (2021): «La panoplia ibérica de guerra recuperada en la torre T3 del poblado protohistórico de l'Assut (Tivenys, Baix Ebre, Tarragona)». Gladius, 41: 45-65. https:// doi.org/10.3989/gladius.2021.03

RECIBIDO / RECEIVED: 16-07-2020

ACEPTADO / ACCEPTED: 10-04-2021

\section{INTRODUCCIÓN}

El conjunto armamentístico recuperado en el poblado ibérico de L'Assut se corresponde con una panoplia ofensiva prácticamente completa, que se conservaba en uno de los principales edificios del yacimiento, la torre T3, destruida intencionadamente a finales del siglo III — inicios del siglo II ANE, en una acción represiva de las tropas romanas (Diloli, 2009). Si bien el asentamiento continuó ocupado durante al menos un siglo más, la torre T3 fue completamente asolada, y nunca se llevó a cabo su recuperación, ni estructuralmente, ni de los bienes conservados en su interior. Este suceso nos ha proporcionado una documentación excepcional sobre el contenido de este espacio en el momento de su derrumbe. Cabe indicar que el hallazgo de armamento de época protohistórica en espacios de hábitat es un hecho poco común, siendo lo habitual su localización en necrópolis (Quesada, 2010, 2011a). El descubrimiento en poblados responde frecuentemente a un hecho excepcional en la vida del lugar, como podría ser una ofrenda ritual (Vives-Ferrándiz et alii, 2015) o, más regularmente, a una destrucción violenta y a veces inesperada que imposibilita su resguardo por parte de sus propietarios, dándose esta generalmente en poblados o asentamientos que son abandonados sin reocupación (Quesada, 2011a). Los datos que presentamos, únicos en el nordeste peninsular por las características del hallazgo, se han incluido a nivel interpretativo en el segundo caso, si bien se trata de una destrucción puntual - un único espacio - en el conjunto del asentamiento.

\section{EL YACIMIENTO}

El yacimiento protohistórico de L'Assut (Tivenys, Baix Ebre, Tarragona) se encuentra ubicado en el margen izquierdo del Ebro, sobre un altozano que controla el acceso meridional del Pas de Barrufemes, desfiladero que se sitúa entre las sierras de Cardó y Àguiles-Vallplana, delimitando el curso del río en su último tramo. Se trata de un asentamiento que ocupa la superficie y ladera sur de una colina, con una superficie aproximada de unos $4000 \mathrm{~m}^{2}$, que domina el amplio llano aluvial que hoy en día conforma las huertas de Tivenys y Xerta (Baix Ebre, Tarragona). Al norte, el límite del yacimiento lo perfila un barranco, el Lligallo de l'Assut, antiguo camino ganadero que asciende desde el margen fluvial hacia las sierras de Cardó y Boix, para desde allí descender al mar. Por el sur, el desnivel no es tan acusado, siendo la pendiente bastante inferior y la accesibilidad más fácil.

Su situación geográfica le concede un control muy importante sobre el territorio que lo rodea, los terrenos aluviales que rodean el río, excepcionalmente aptos para la agricultura, las terrazas cuaternarias circundantes, actualmente ocupadas por cultivos de secano - vid, olivos y algarrobos-, y las zonas más elevadas de las sierras. Además, su posición estratégica le proporciona una amplia visibilidad sobre el río Ebro, principal vía de comunicación entre la costa y el interior peninsular durante la Antigüedad.

Las intervenciones efectuadas en el yacimiento, iniciadas en el año 2000, han permitido distinguir varias fases de ocupación que se extienden entre finales del siglo VIII ANE y el primer tercio del siglo I ANE, ejemplificando en la zona del curso inferior del Ebro la ocupación continuada de un espacio que se habitaría durante prácticamente toda la Protohistoria. La secuencia es la siguiente:

- Fase Assut 0A: Posiblemente la más desconocida dada su ocultación y transformación por las fases posteriores. Se conoce un único muro alzado mediante la técnica de ortostatos, situado al norte, en la parte más elevada del cerro, en el espacio donde se erige el sistema defensivo de época ibérica. No mantiene relaciones estratigráficas con ninguna estructura de época posterior, 

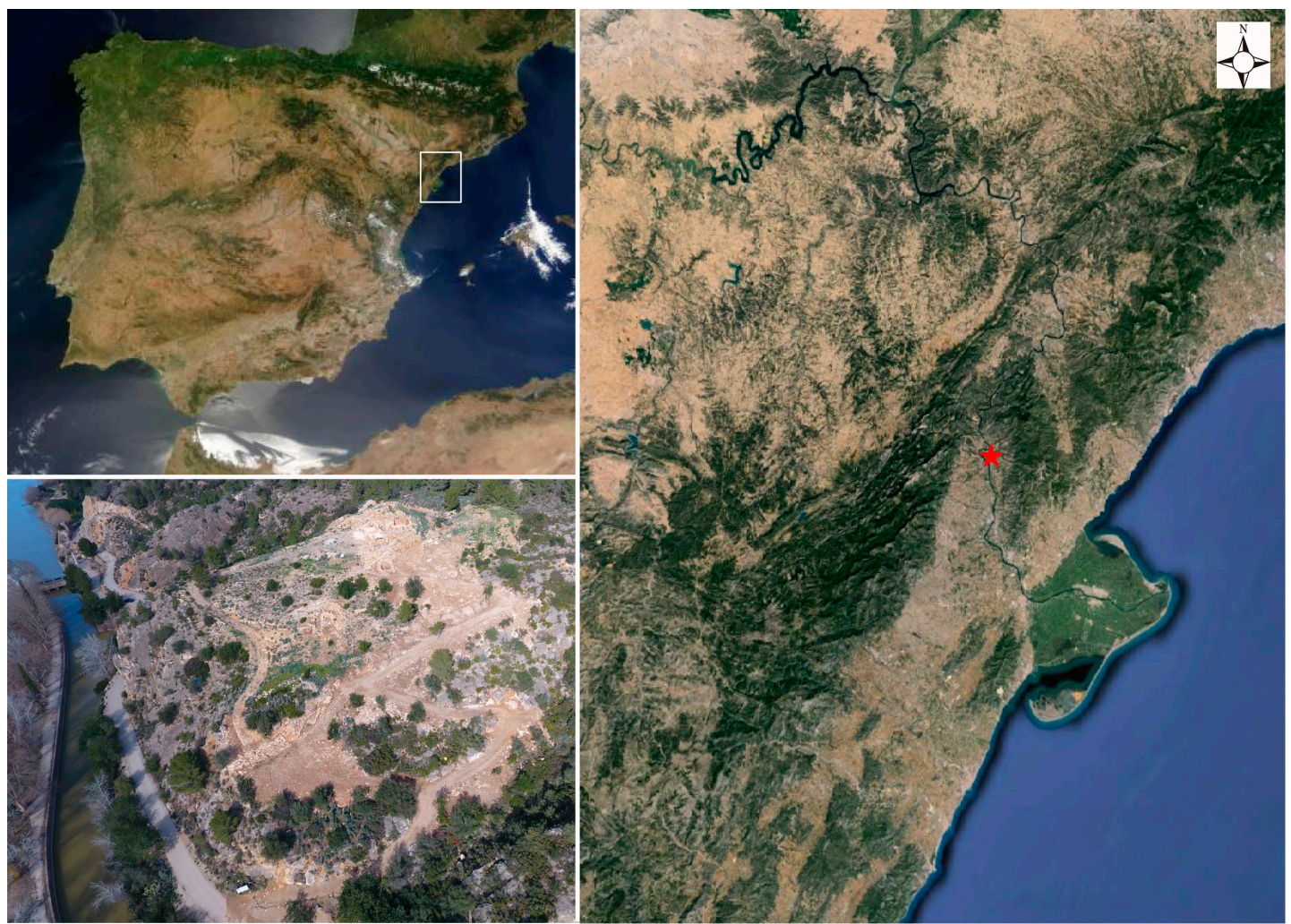

Figura 1. Situación del yacimiento arqueológico de L'Assut (Tivenys, Baix Ebre, Tarragona). GRESEPIA.

$\mathrm{y}$, a pesar de la proximidad espacial con el conjunto murario que dio lugar a la fase Assut $0 \mathrm{~B}$, su orientación en sentido este-oeste demuestra que no tiene nada que ver con este. Su datación se ha efectuado a partir de su asociación con algunos fragmentos de ánfora fenicia del tipo T.10.1.1.1, fechándose entre los siglos VIII y VII ANE.

- Fase Assut 0B: Sobre el límite norte de la colina se ha dejado al descubierto una agrupación estructural que parece constituir una batería de habitaciones que presenta una delimitación arquitectónica de compleja interpretación, sobre todo a causa de la superposición de muros de periodos posteriores. Para la construcción de este conjunto se llevaron a cabo importantes esfuerzos de nivelación, erigiéndose gruesos muros capaces de sostener no solo el peso del alzado de los propios edificios, sino también de una importante acumulación de relleno interno, en el que se han localizado, entre otros, fragmentos de ánfora fenicia T.10.1.2.1, así como diversos materiales de tipología aparentemente fenicia, ánforas, pithoi o platos que imitan las producciones a torno procedentes del área del Círculo del Estrecho (Diloli et alii, en prensa). La presencia de estas cerámicas nos ha permitido datar esta fase durante la Primera Edad del Hierro, concretamente durante la etapa 1A (700-550 ANE) (Bea, 2012; Diloli, 2018).

- Fase Assut 1: Representada por la construcción de un edificio que en un primer momento estaría aparentemente exento, y que a partir de finales del siglo V ANE quedaría incorporado al sistema defensivo del poblado ibérico. Se trata de una torre de planta circular (T3), con el interior habilitado para ser usado como espacio doméstico. Cuenta con una superficie útil de $18 \mathrm{~m}^{2}$, y se ha documentado al menos una planta superior que, teniendo en cuenta el notable grosor del muro perimetral, que oscila entre 2 y $2,2 \mathrm{~m}$, podría completarse con un segundo piso. La datación de su construcción se sitúa de manera aproximada durante el siglo VI ANE (Diloli, 2009). De hecho, no se puede descartar completamente que coexistiera durante algún tiempo con las casas de la fase Assut 0B.

A nivel interpretativo, situamos la torre $\mathrm{T} 3$ de L'Assut como el resultado de la difusión en el tramo inferior del valle del Ebro de un tipo de arquitectura con una tendencia a arquetipos de planta circular, que a partir del siglo VI ANE se 
convierte en la expresión constructiva utilizada por un grupo social privilegiado para remarcar su autoridad y desemejanza con el resto de la comunidad, una élite que se aislará mediante la edificación y ocupación de unos edificios fortificados segregados desde donde exhibirá su poder sobre el territorio. Este modelo constructivo fue diferenciado por Pierre Moret en el Bajo Aragón-Matarraña (Moret, 2002; Moret y Chapa, 2004; Moret et alii, 2006), identificándose posteriormente la expansión del modelo a otros territorios (Bea et alii, 2012; Diloli, 2018). Si bien en un principio el fenómeno de la aparición de estas casas-torre se trató como claramente datable a partir del 550 ANE, sin prolongarse más allá del paso entre la sexta centuria y el siglo V ANE, hoy en día sabemos que el modelo tiene un inicio, o quizás mejor una fase de tanteo, en momentos anteriores que pueden remontarse hasta el tránsito entre los siglos VII y VI ANE, y que en algunos casos perviven más allá de estas fechas, adaptándose a nuevos tipos urbanísticos, como sería el caso de la torre del Coll del Moro de Gandesa y de la torre T3 de L'Assut, en este caso constituyendo una estructura que forma parte de casi toda la historia del yacimiento.

- Fase Assut 2: A partir de finales del siglo V ANE, se produjo el despliegue urbanístico de un poblado de dimensiones bastante mayores que los asentamientos precedentes, hecho que coincide con la iberización plena de la región. El nuevo asentamiento ocupó el extremo superior del cerro y seguramente desde el primer momento, la vertiente sur, aislándose del exterior con una potente fortificación de la cual T3 pasó a formar parte, protegiendo el flanco de un sistema defensivo que se extiende entre los dos barrancos que delimitan el espacio de hábitat, para descender hacia la base de la colina por la ladera meridional. En el punto más alto se aprovechó constructivamente una pequeña elevación del terreno natural, forrándola con muros superpuestos que delimitan terrazas a distintos niveles. El volumen de la obra y las características irregulares del suelo motivaron una edificación compleja y singular, utilizándose la técnica de paramentos múltiples para asegurar la estabilidad. El complejo superior resultante se estructura a partir de un pasillo central que lo atraviesa en sentido longitudinal desde su extremo noroeste (T1) hasta alcanzar la torre T3, que tendría una puerta a la altura del primer piso para permitir la circulación por el mismo. En este mismo momento constructivo la torre T3 fue forrada con un nuevo muro externo, aumentando así el grosor perimetral hasta los $4 \mathrm{~m}$. Esta muralla se extiende salvando las curvas de nivel hasta la cota más baja del poblado, adaptándose al terreno y protegiendo los puntos más débiles del poblado ibérico, reforzándose con distintos paramentos allá donde el desnivel es más suave y accesible.

Hay que destacar la complejidad arquitectónica del sector sursureste del asentamiento, donde la pendiente es más gradual. Justo en este punto arranca un tramo de muralla constituida por una potente estructura pétrea de la que se conocen, de momento, cerca de $18 \mathrm{~m}$ de longitud, con una anchura de aproximadamente $2,5 \mathrm{~m}$. Esta muralla sigue, en apariencia, un peldaño natural rocoso de la misma colina, y su paramento semi-megalítico está compuesto por grandes bloques desprendidos del substrato. La continuidad de la muralla hacia la zona más elevada del poblado se efectúa en tramos dispuestos en cremallera, quizás para salvar el desnivel, confiriéndole al mismo tiempo un remarcable aspecto defensivo. Pero quizás lo más interesante es la localización en el extremo inferior del trazado de este paramento de una puerta que estaría atravesada por una canalización que permitiría evacuar las aguas pluviales acumuladas por las escorrentías de la colina. Destaca la presencia en la muralla de por lo menos dos torres más: la primera (T4), situada en una cota más baja, protegiendo un camino interno de acceso, con diversas reformas, y la segunda (T5), asociada al cierre del poblado por el extremo superior, bastante cercana a T3 y exenta a la muralla.

En el lado norte, la delimitación y protección edificada del poblado la conformaría la pared posterior de las casas, si bien hay que destacar la existencia de algunos paramentos externos al muro de cierre, de momento de difícil interpretación, que podrían asociarse a la defensa del poblado.

En cuanto al área de hábitat, los datos actuales indican que el altozano fue urbanizado durante esta fase a través de la construcción de una serie de viviendas que se extenderían por la cima y la ladera sur. En el extremo superior, las casas, de modestas dimensiones, se estructuran en torno a una calle central $(\mathrm{C} 1)$ de la que se ha documentado un tramo en forma de rampa recortada en la roca. Una segunda calle o vía (C2) transcurre en paralelo al sistema defensivo superior por el lado interior, perpendicular a la calle central, formando un esquema viario básico en forma de T. En el denominado barrio norte ( $\mathrm{ZHN})$, las antiguas construcciones de la fase $0 \mathrm{~B}$ fueron reutilizadas como 
cimentación para edificar nuevos ámbitos, que podrían haber sido estructurados en dos niveles escalonados: un primer nivel sobre la cresta del peñón, y un segundo en una cota inferior, apoyado sobre las casas de la Primera Edad del Hierro. Las dos reformas detectadas en la posterior fase 3 habrían destruido parte del entramado arquitectónico de la fase 2 , hecho que dificulta la posibilidad de discernir si estos dos niveles llegaron a generar dos pequeñas baterías independientes de casas, o tan solo una, con viviendas que hubiesen tenido el suelo en dos alturas. Tanto las dimensiones como la complejidad interna de las viviendas de este periodo son reducidas, destacando su adaptación a la pendiente, hecho que requirió de esfuerzos suplementarios de nivelación que dificultó la construcción de habitaciones amplias. En todo caso, la presencia de bases de columna en algunas estancias presupone una construcción en altura, ya sea un altillo o un piso superior.

En la vertiente sur se sitúa otro barrio - ZHS - que ha sido objeto de excavaciones los últimos años, aunque su conocimiento es aún limitado. Se trata de un sector bastante afectado tanto por la antropización como por la erosión, en el que se evidencia la existencia de, como mínimo, cuatro plataformas escalonadas que conforman terrazas estrechas, de menos de $5 \mathrm{~m}$ de ancho, en intervalos irregulares. Los espacios residenciales adaptados a estos condicionantes seguramente tampoco serían muy espaciosos, a no ser que contasen con un piso superior y un posible acceso a dos niveles aprovechando la vertiente de la ladera.

Uno de los aspectos más destacables que se ha puesto de manifiesto en relación con la urbanización de este sector es su sistema viario. La adaptación al desnivel natural y la necesidad de conexión entre la parte baja y la superior del asentamiento promovieron un procedimiento complejo de accesos a partir de un camino que avanza en perpendicular a las curvas de nivel de la colina para, más adelante y después de superar por lo menos una plataforma constructiva, girar $90^{\circ}$ hacia el oeste adaptándose al relieve. La anchura del camino no es uniforme, oscilando entre 1 y 1,70 m según el punto del trazado. Este acceso se bifurca en un punto a media ladera, dando lugar a dos vías diferentes; por un lado, un ramal sigue remontando la ladera por medio del uso de escalones de piedra que van a parar a un camino recortado en parte sobre la roca natural que, aparentemente, se dirige al extremo superior del poblado, junto a la torre
T3. El otro ramal, muy afectado por la erosión, recorre la vertiente en forma de calle estrecha respetando la curva de nivel, en dirección al extremo oeste del barrio.

Fase Assut 3: A partir de finales del siglo III - inicios del II ANE se produjeron una serie de transformaciones en el poblado que dejaron una profunda huella en su urbanismo y arquitectura. No está claro hasta qué punto estos cambios están relacionados entre ellos, pero se puede asegurar que se llevaron a cabo en un margen temporal bastante reducido, afectando tanto al sistema defensivo como al espacio doméstico, de la siguiente forma:

1. Se remodeló en profundidad la batería de casas situada al norte del poblado, cuyo espacio fue acaparado por dos únicos edificios de mayores dimensiones que los precedentes, con una complejidad interna superior, evidenciada por la aparición de estancias y compartimentaciones más reducidas. Los materiales asociados a los niveles de uso y abandono de estos dos ámbitos se sitúan principalmente durante el siglo II ANE.

2. Destrucción de la torre T3. Justo a finales del III ANE - inicios del II ANE, la torre T3 sufrió un devastador incendio que provocó su destrucción y abandono, a pesar de que el resto del poblado siguió habitado. El estado de rubefacción de las piedras indica que se alcanzaron temperaturas muy elevadas, probablemente relacionables con una destrucción intencionada. La magnitud del fuego revela que no se hizo nada para apagarlo, ni hubo ningún intento posterior al mismo de rescatar los objetos muebles que contenía el edificio, entre los que abundaban los artefactos metálicos, ni tampoco ninguna tentativa para reconstruir o, como mínimo recuperar, el espacio ocupado por la torre. Ni siquiera se llevó a cabo ningún esfuerzo para desescombrar el lugar. Estas circunstancias nos inducen a pensar en una acción punitiva con algún trasfondo simbólico.

3. Remodelación parcial del sistema defensivo. La destrucción de la torre T3 obligó a reestructurar arquitectónicamente todo este espacio. El pasillo que comunicaba longitudinalmente las diferentes partes de la fortificación fue inutilizado mediante la construcción de un muro que lo tapió, rellenándose el interior con tierra, vertida intencionadamente en su parte central, aislando los escombros de la torre T3. El extremo norte del pasillo (T1) habría seguido en uso en estos momentos, aunque se desconoce con qué función. Así pues, la estructura defensiva perdió gran parte 


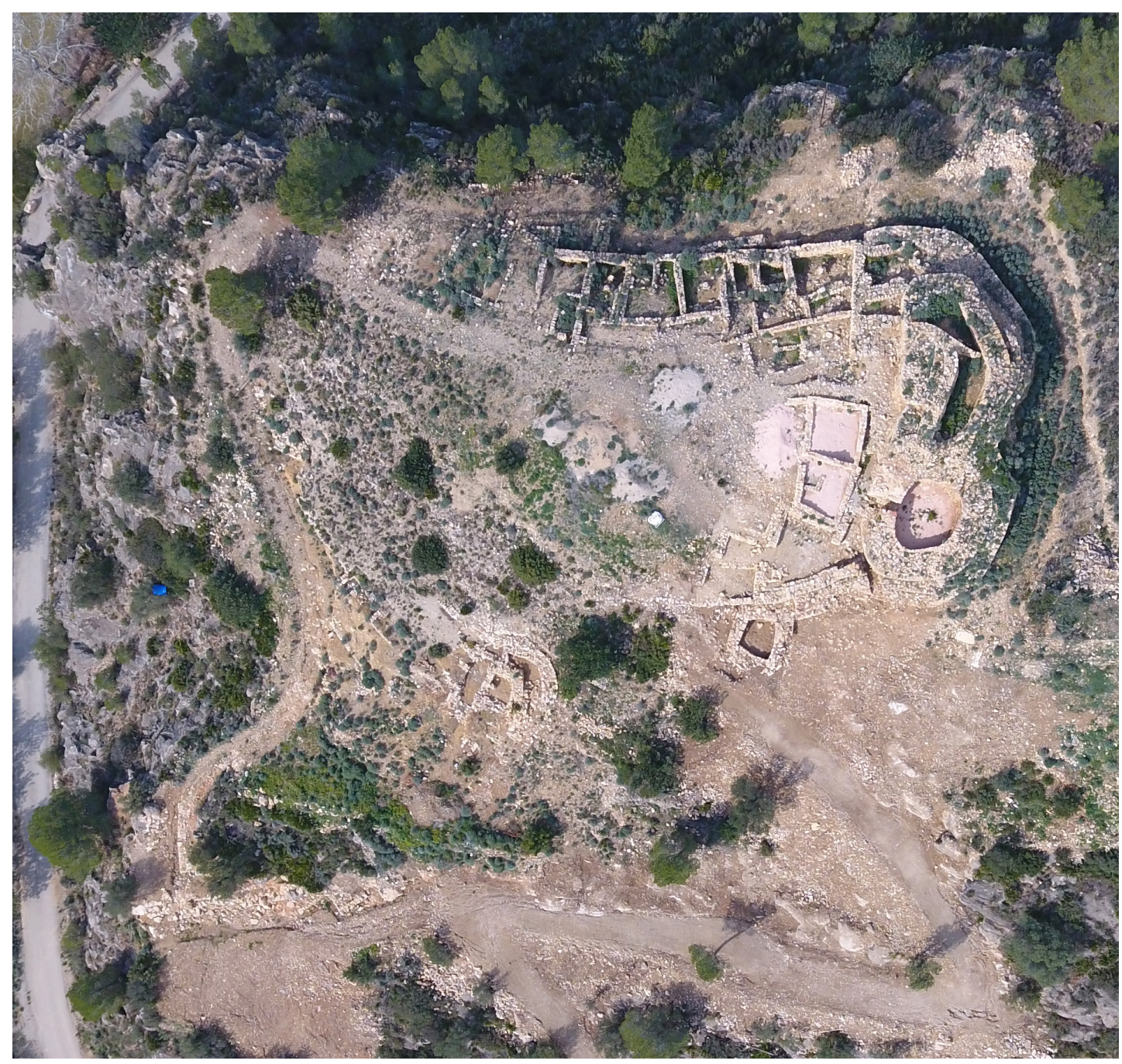

Figura 2. Fotografía aérea del yacimiento. GRESEPIA.

de su esencia original, a pesar de que el poblado siguió funcionando hasta por lo menos el último tercio del siglo II ANE, momento en que fue abandonado pacíficamente.

- Fase Assut 4: Hay indicios que durante el primer tercio del siglo I ANE un pequeño porcentaje de la superficie del poblado estuvo ocupado. La reducida cantidad de materiales de esta época que se han recuperado no permite afirmar con seguridad si se trata de una continuidad en la función residencial de algunas casas, o si más bien se trata de una frecuentación de estos espacios. El barrio sur parece estar ya definitivamente deshabitado y el sistema defensivo abandonado. Solo hay muestras inequívocas de ocupación en el sector central del promontorio, focalizándose esta ocupación en el entorno del edificio A16/17, que habría podido pervivir durante la primera mitad del siglo I ANE, según indica la presencia de campaniense B. También se constatan algunas muestras de actividad constructiva, básicamente reforma de muros, en el sistema defensivo superior.

\section{LA TORRE T3}

El edificio turriforme de planta circular (T3), asociado al sistema defensivo, es, como ya hemos indicado, uno de los elementos más excepcionales del yacimiento de L'Assut. Situado en el extremo superior de la colina e incorporado a las fortificaciones del poblado de época ibérica, subsiste a 


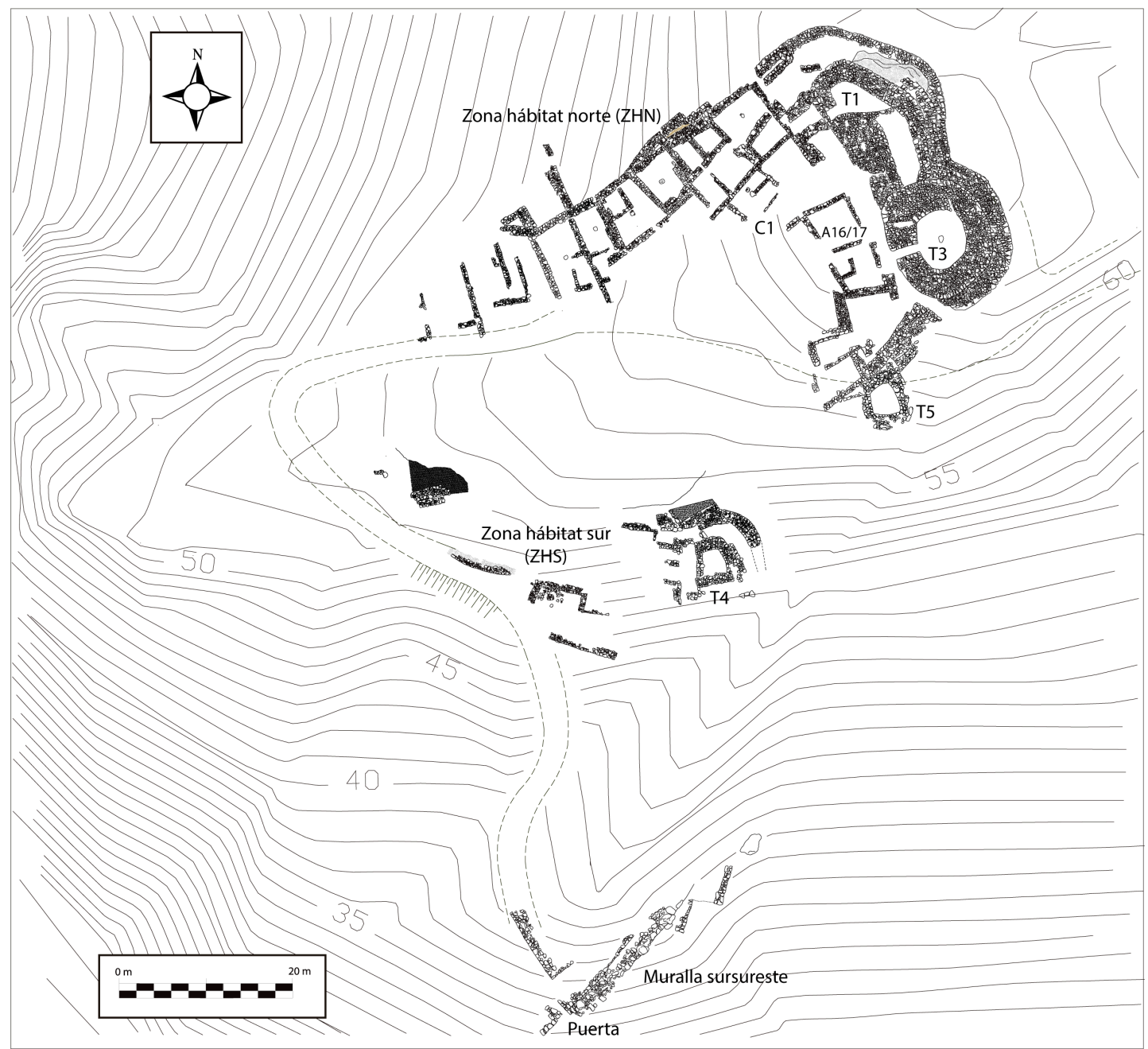

Figura 3. Planta topográfica del yacimiento con indicación de zonas y espacios citados en el texto. GRESEPIA.

lo largo de casi todas las fases de ocupación del asentamiento hasta su violenta destrucción en torno al paso del siglo III al II ANE.

$\mathrm{Su}$ interior presenta tres unidades estratigráficas principales: UUEE 1304, 1306 y 1308. La UE 1304 está formada por la sedimentación asociada al derrumbe de la parte superior de la estructura, con presencia de restos del incendio que la destruyó, siendo de formación posterior a la cremación, si bien en algún punto las UUEE 1304 y 1306 aparecen mezcladas. Por debajo de esta se encuentra la UE 1306, un nivel que se corresponde directamente con el derrumbe del primer piso de la torre, en el cual se localizaron un número elevado de pondera y algunos de los materiales metálicos más significativos. En el estrato inferior encontra- mos la UE 1308, del mismo momento cronológico, formando parte también del derrumbe interno de la estructura y situada directamente encima del último pavimento de uso (UE 1311), cubriendo parte de la estructura de piedra (UE 1310) que servía de base a un pilar central de madera, que sostenía una viga y algunos travesaños, parte de los cuales pudimos recuperar carbonizados. Hay que indicar el hallazgo entre los elementos de este estrato de una moneda romana acuñada en Cerdeña en el año 209 ANE. Asociado a la UE 1311, compuesta por una capa de arcilla fina, se halla la UE 1312, relacionada con un hogar (UE 1317). Las UUEE 1313 y 1314 se corresponderían con niveles de regularización/relleno del suelo de la torre, siendo 1315 el terreno natural (Fig. 5). 
Es en este contexto estratigráfico del interior del edificio donde se localizó el conjunto de armamento y objetos metálicos que presentamos en el artículo. Como parte de la panoplia militar se exhumaron una punta de lanza, un regatón, una falárica, un soliferreum y un cuchillo afalcatado, además de algunos fragmentos metálicos indeterminados que podrían formar parte de otros efectos de más difícil clasificación. Así mismo, se recuperaron una serie de herramientas relacionadas con la producción agrícola y las tareas domésticas que ampliarían, a nivel interpretativo, el interés del conjunto. Entre estas destacan, por su buen estado de conservación, un podón, una podadora, un rastrillo y una azadilla, cuatro objetos que componen un grupo de utensilios agrícolas que podrían indicar cierta especificidad relacionada con el trabajo vitivinícola.

Por lo que respecta al podón, un apero muy bien representado en yacimientos ibéricos, se trata de una pieza de hoja ancha y robusta, con enmangue tubular y un agujero en su extremo para inserir una traviesa de fijación; tiene una longitud máxima de $22 \mathrm{~cm}$, una anchura máxima de hoja de $4 \mathrm{~cm}$ y un grosor de $6 \mathrm{~mm}$, siendo el diámetro máximo del enmangue de aproximadamente 2,5 $\mathrm{cm}$. Funcionalmente, podríamos clasificarlo como una herramienta multiusos, ya que sirve para múltiples tareas del trabajo agrícola: desbrozar, podar, cortar o limpiar, entre otras.

La podadora, muy relacionada con el podón, tiene unas características propias que la convierten en un objeto de trabajo bastante exclusivo. De formas similares, las diferencias básicas son el tamaño y el cierre más pronunciado de la curva de la hoja. Algunos autores han propuesto una vinculación directa de estos utensilios con la poda y cosecha de la vid (Rovira, 1994). El ejemplar exhumado en la torre T3 de L'Assut es el único del curso inferior del Ebro identificado como tal sin ninguna duda. Los podones y las podadoras aparecen en el mundo ibérico a partir del siglo IV ANE, extendiéndose hasta el siglo II ANE y perdurando en forma y función prácticamente hasta nuestros días.

En el caso del rastrillo, se trata de un objeto asociado indirectamente a la azada, con una función de mantenimiento de los campos de cultivo. Se compondría de una vara larga de madera con una paleta de hierro en su extremo, con la que se retiraba la tierra removida. En el caso de L'Assut, el rastrillo estaría asociado a la azadilla, herramienta que se usaba para mezclar y agujerear la tierra, y que se conservaba íntegramente en el interior del mismo edificio, siendo también una pieza única en todo el curso inferior del Ebro. Es un utensilio relativamente simple, con una hoja con forma de plancha de azuela, ligeramente curvada, que forma un ángulo agudo por el enmangue del agujero. De dimensiones reducidas, la hoja tiene $15 \mathrm{~cm}$ de longitud máxima y unos $6 \mathrm{~cm}$ de anchura máxima, su grosor es de difícil determinación debido a la fuerte oxidación que presenta. A unos $2 \mathrm{~cm}$ de la parte posterior del mismo hay un orificio circular de unos $3 \mathrm{~cm}$ de diámetro que serviría para insertar el mango de madera. Reconocido como un utensilio para cavar ligeramente, pero sin profundizar, su uso se podría relacionar con cultivos específicos, como por ejemplo la vid, donde es preciso airear la tierra de manera frecuente, cavando surcos cercanos a la planta. De hecho, esta función encajaría con la funcionalidad del resto de herramientas agrícolas descritas ${ }^{1}$.
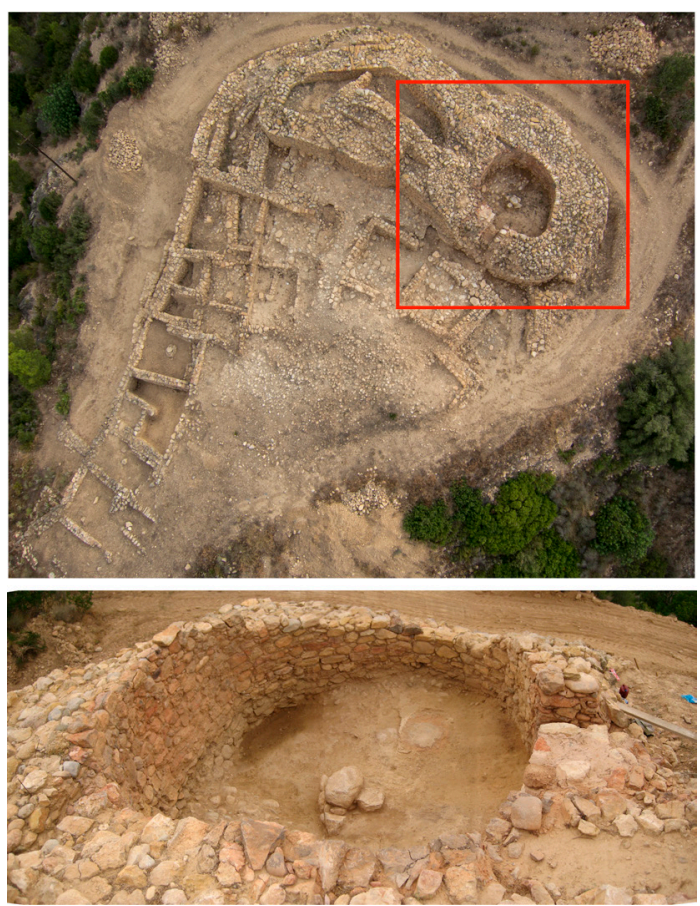

Figura 4. Situación y detalle de la Torre T3. GRESEPIA.

${ }^{1}$ Agradecemos a Laura Bricio, del GRESEPIA, la descripción y los comentarios sobre las herramientas agrícolas, así como su interpretación en relación con el cultivo de la vid. 


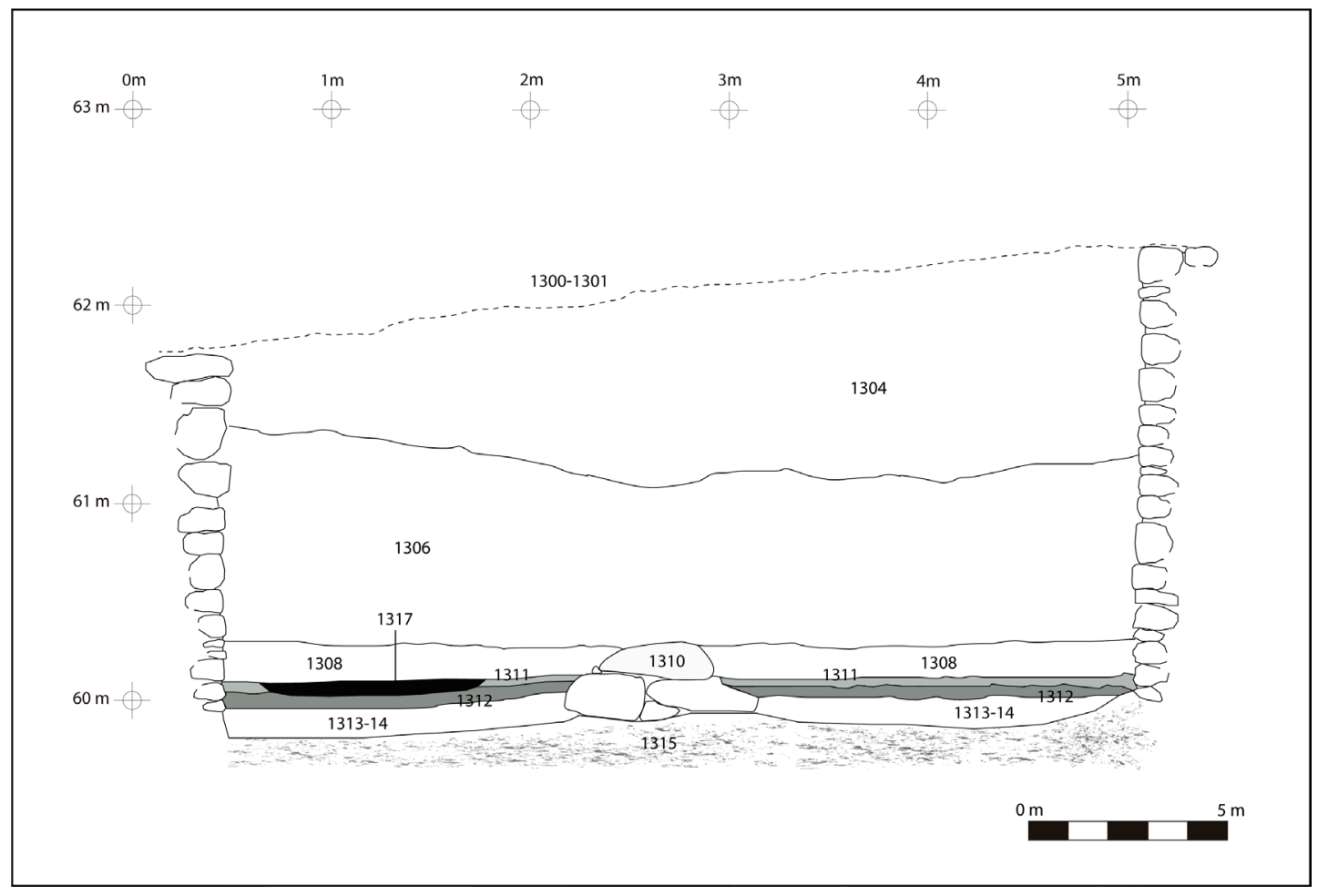

Figura 5. Sección estratigráfica de la Torre T3. GRESEPIA.

Además de estos objetos, obviando el conjunto armamentístico, hay que destacar la presencia de un hacha, una posible reja de arado, un asador y los fragmentos de una posible parrilla de hierro, así como otros elementos de difícil definición: placas de distintos tamaños, algunas agujereadas, clavos, anillas, grapas y varillas. Destaca también la presencia de piezas de bronce, asociadas al ornamento o atavío personal (pequeñas anillas, un posible fragmento de hebilla y una fíbula) y algunos fragmentos de plomo - placas o pequeños pesos-, que se pueden relacionar seguramente con actividades artesanales o de pesca.

\section{DESCRIPCIÓN Y CONTEXTUALIZACIÓN DE LAS PIEZAS ARMAMENTÍSTICAS RECUPERADAS EN LA TORRE T3 DE L'ASSUT}

Si bien el estudio del armamento ha sido una constante en la investigación de los pueblos protohistóricos peninsulares, no es hasta hace relativamente poco que gracias a trabajos de tipo individual, entre los que destacan especialmente los efectuados por Fernando Quesada (1992, 1993,
1997, 1998, 2002, 2003, 2005, 2006, 2007, 2009, 2010, 2011a, 2011b), los de Pérez Daza (2003) o García Jiménez (2006, 2011, 2012) o colectivos, como los de Farnié y Quesada (2005) o Mateos y Sánchez (2014), entre otros, que el conocimiento y la determinación cronológica, funcional y simbólica de las panoplias defensivas y ofensivas de los pueblos ibéricos no ha avanzado suficientemente como para convertirse en un elemento esencial para el progreso en el conocimiento de una sociedad que hizo de las armas una enseña que iba mucho más allá de su funcionalidad, al representar tanto estatus como posición social y seguramente política.

La presencia de armamento no es escasa en la arqueología ibérica, pero muy inferior sin duda a la cuantificación que tuvo en su propio contexto histórico. Son diferentes los espacios que nos ofrecen información sobre las armas de los íberos: aparecen directamente en asentamientos, en necrópolis y en espacios de culto, como ofrendas, así como indirectamente en conjuntos escultóricos, pintadas sobre cerámica o figurando en las acuñaciones de las monedas, escenificando el valor que tenían para sus poseedores. Guerreros que bailan, luchan o cazan, nos muestran la importan- 
cia del armamento en la cotidianidad ibérica; tanta, que las armas fueron el más fiel compañero en el viaje al más allá, inutilizadas ritualmente y destinadas a acompañar eternamente a su poseedor.

Tal y como apunta Quesada, el armamento ibérico no surge de la nada (Quesada, 2011b). Durante la segunda fase de la Primera Edad del Hierro (550-450/25 ANE) (Bea, 2012; Diloli, 2018), en el noreste peninsular se asiste a un cambio sociopolítico, heredero de la etapa anterior, que cristaliza en la ascensión al poder de una aristocracia guerrera que promueve la exclusividad de su prestigio a partir de manifestaciones que transitan por una arquitectura singular - casas fortificadas - , como ya hemos indicado, y por un tipo de enterramiento distintivo donde buena parte de las ofrendas pasan por la panoplia armamentística (Bea et alii, 2012).

Este panorama, por lo menos tal como lo indican los datos arqueológicos, sufre una profunda transformación durante los siglos V a III ANE, en lo que venimos llamando Ibérico Pleno. En este momento desaparecen las casas fortificadas, algunas destruidas, otras integradas en poblados de nueva planta, como en el Coll del Moro de Gandesa o L'Assut de Tivenys, perdiéndose el rastro de las necrópolis prácticamente hasta la presencia romana. Esto no quiere decir que las armas dejasen de tener su papel primordial en la sociedad ibérica, pero su presencia en contextos arqueológicos es mucho más inusual, en buena parte seguramente por la ausencia de necrópolis durante este periodo en este espacio geográfico ${ }^{2}$.

A partir del siglo III ANE, concretamente durante el último tercio, aparece una modalidad armamentística que Fernando Quesada ha denominado "panoplia renovada" (Quesada, 1997, 2002), en un entorno de generalización del armamento, más efectivo frente a los nuevos tipos de guerra "mundial" de la época (Quesada, 2011b). Es en este momento cuando la península ibérica se convierte en uno de los escenarios donde las dos grandes potencias mediterráneas del momento, Cartago y Roma, se enfrentarán, influenciando e induciendo la adaptación armamentística por parte de las poblaciones indígenas, generando incluso cierto feedback con el ejército romano, como

\footnotetext{
${ }^{2}$ Hay que indicar que los estudios realizados hasta el año 2011 indicaban que solo el 13,4\% de los materiales armamentísticos encontrados en yacimientos ibéricos lo eran de espacios de hábitat, en contraposición al 77,1 \% procedentes de contextos funerarios (Quesada, 2011a).
}

es el caso, por ejemplo, de la adopción del gladius hispaniensis por las legiones romanas (Quesada, 1997, 2007). Los elementos ofensivos más habituales de esta panoplia están constituidos por las lanzas, las espadas, los soliferrea y las jabalinas, observándose una tendencia a la simplificación y utilización de material más ligero que en periodos anteriores.

Los materiales recuperados en la torre T3 de L'Assut se corresponden con este preciso momento. Dadas las características de su destrucción y posterior abandono, perfectamente fechado, se ha podido recuperar un lote que representaría la panoplia de un guerrero ibérico, seguramente propia de su posición social e incluso de su rango, a finales del siglo III ANE.

El primer elemento localizado, aparecido en la UE 1306, es una punta de lanza de hierro (Fig. 6). La pieza está entera, con unas medidas de 14,5 $\mathrm{cm}$ de longitud total, de los cuales $7,5 \mathrm{~cm}$ corresponden a la hoja, siendo su anchura máxima de $2,8 \mathrm{~cm}$. El diámetro externo del enmangue, de tipo tubular, es de $2,5 \mathrm{~cm}$ y el interno de $1,5 \mathrm{~cm}$. La sección de la hoja, de difícil definición a causa del mal estado de conservación de la pieza, parece aplanada, con un ligero engrosamiento central. No se observa ningún nervio ni arista.

Si bien este tipo de arma es muy abundante en época ibérica, y su tipología muy diversa, tanto por forma como por dimensiones, sus características apuntan a que podría tratase del tipo 4Aiic7 o 11 de Quesada, un tipo de punta de hoja triangular ancha, habitual en Cataluña, y con una cronología amplia que abarcaría desde el siglo IV al II ANE (Quesada, 1997: 363).

Esta punta sería el remate de un astil de madera de longitud desconocida, si bien a partir de los datos arqueológicos procedentes del ámbito galo en época de La Tène, se ha propuesto un tamaño que oscilaría entre 2,4 y $3 \mathrm{~m}$, aunque para época ibérica se ha sugerido una longitud total menor, de entre 1,75 y 2,5 m (Quesada, 1997: 346).

El asta terminaría opcionalmente con otro elemento de hierro, el regatón, que en este caso también se ha localizado en el mismo estrato (UE 1306). Se trata de una pieza formada por un componente cónico de hierro, que se colocaría en el talón del astil, actuando a la vez de contrapeso y de punta, sirviendo tanto para clavar la lanza en el suelo, como para sujetarla y proteger la madera, o incluso como un arma circunstancial si se rompía la lanza o había que rematar al enemigo caído. Las medidas del regatón de la torre T3 son 11,4 cm de 
longitud y $2,5 \mathrm{~cm}$ de diámetro externo en la zona de la embocadura, mientras que el diámetro interno sería de 1,5 cm, idéntico al de la punta. En el extremo inferior presenta una concreción metálica resultado de la oxidación.

Los regatones ibéricos tienen muchísimas variedades formales. En todo caso, su simplicidad invita a no establecer filiaciones (Quesada, 1997). La sencillez de estas piezas lleva a una determinación cronológica bastante clara: los regatones más antiguos, del VI-V ANE son largos o muy largos, superando los $25 \mathrm{~cm}$, con excepciones poco numerosas, para, con el paso de los siglos y sobre todo a partir del siglo III ANE, ir disminuyendo la longitud.

Hay que remarcar que la lanza era una de las armas más usuales e importantes manejadas por los guerreros de los pueblos prerromanos de la península ibérica, incluso más que espadas y puñales. Servía tanto para el combate a distancia como, en el caso de las más pequeñas, para la lucha cuerpo a cuerpo. De hecho, a partir del Ibérico Pleno, la panoplia ibérica combinaría varias armas ofensivas de asta, lanzas más bien cortas, para ser empuñadas o arrojadas, asociadas a lanzas pesadas, como los soliferrea. Desde el siglo III ANE en adelante, parece ser que las lanzas reducirían su longitud, siendo más frecuentes las que no tendrían nervio, predominando en el área catalana los prototipos de La Tène (Quesada, 1997: 600).
En la misma unidad estratigráfica (UE 1306) se recuperó otra arma de hierro, en apariencia arrojadiza, de difícil clasificación, pues no puede ser considerada una punta de lanza al estilo tradicional, ni un soliferreum, ni posee las características de lo que genéricamente llamaríamos pilum (entendido como un arma arrojadiza pesada). En todo caso sus características nos han hecho clasificarla como una posible falárica (Fig. 7).

Fragmentada en dos partes, en un extremo tiene una punta de aletas de tendencia lenticular, aunque la oxidación no permite asegurarlo con certeza. El otro extremo tiende a disminuir en grosor, hasta terminar en una punta simple, formando una espiga que permitiría integrarla a un astil de madera. Su sección es rectangular y no se observa ninguna nervadura. La longitud del objeto es de $30,5 \mathrm{~cm}$, de los que $5,5 \mathrm{~cm}$ son de la punta y 5,5 $\mathrm{cm}$ del extremo inferior; la anchura máxima de las aletas a la punta es de $2,5 \mathrm{~cm}$ y las medidas de la sección son $1,5 \mathrm{~cm}$ x $0,8 \mathrm{~cm}$. A unos $10 \mathrm{~cm}$ de la punta se observa un nódulo metálico que no se puede precisar si es parte del original o una deformación debido al proceso de oxidación.

Tal y como se observa, el arma es de difícil clasificación, pues no tiene el enmangue habitual en los pila romanos, que en este caso ha sido sustituido por una espiga que permitiría la unión entre la punta de hierro y el asta de madera. Livio, en su descripción del asedio de Sagunto, menciona un arma arrojadiza usada por los saguntinos,

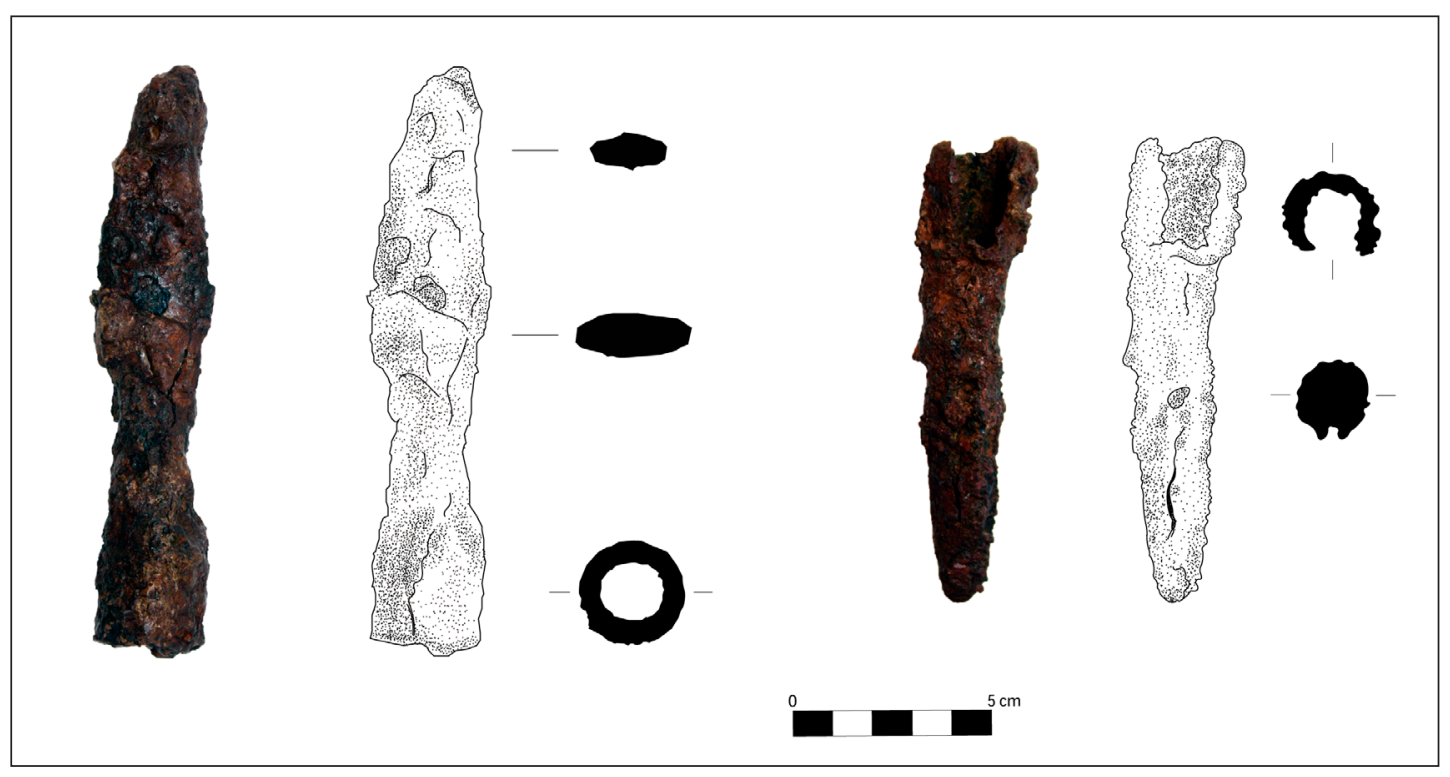

Figura 6. Punta de lanza y regatón. GRESEPIA. 


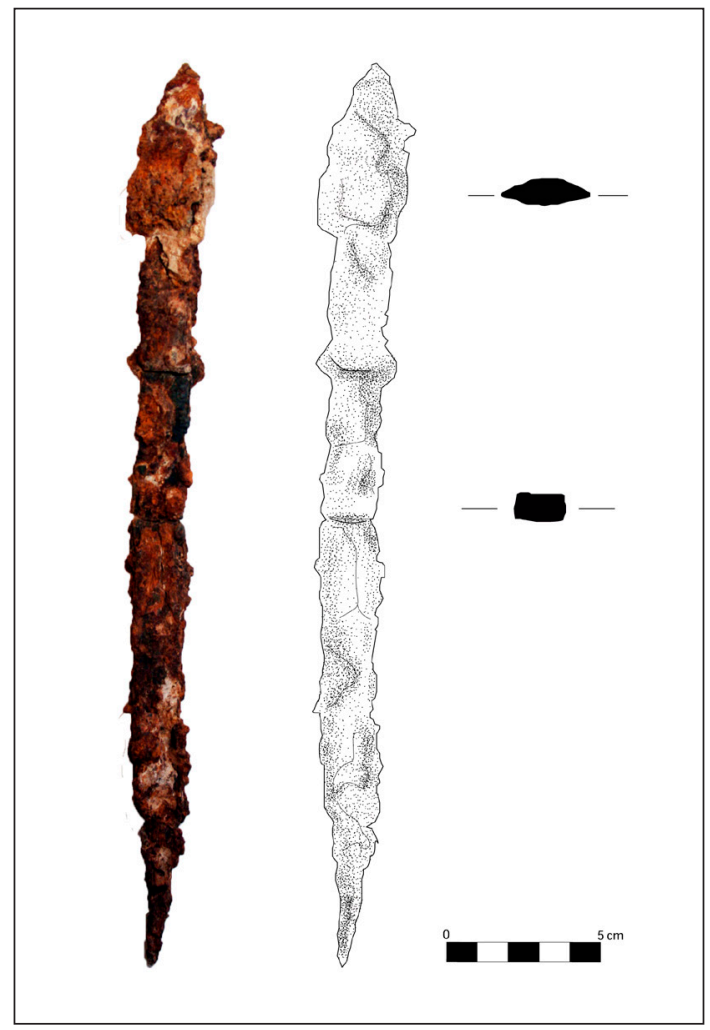

Figura 7. Falárica. GRESEPIA.

la falárica, de asta de abeto y extremo de hierro, que compara al pilum, pero distinguiendo ambas (Livio, XXI, 8, 10). Schulten en su momento interpretó que phalarica y pilum serian lo mismo, especificando que en el pilum ibérico de cubo, la madera se insertaba en el hierro, mientras que la falárica de los saguntinos es un pilum en el que el hierro se introducía en la madera, «es decir, un pilum de espiga» (Schulten, 1943: 1342). Fernando Quesada refuta esta versión de Schulten, haciendo notar que ningún pilum ibérico conocido coincide con esta descripción (Quesada, 1997: 335). Según su criterio se trata de un asunto de difícil clarificación, pero es innegable que la falárica es un arma de astil mixto, en parte de madera y en parte de hierro, diseñada para ser arrojada (Quesada, 1997: 336). Esta seria pues la posible función del arma exhumada en T3. Llamarle o no pilum o falárica es únicamente dotarla de un nombre propio, que hoy por hoy es difícil asignar. Si la consideramos dentro de esta categoría de arma de asta pesada, concebida para ser lanzada, teniendo en cuenta la punta de la pieza, de forma foliácea, sin nervio aparente y de unos $8 \mathrm{~cm}$ de longitud, podríamos incluirla en el tipo II propuesto por Quesada: puntas sin nervio, con arista central y sección romboidal (Quesada, 1997). La longitud total de las piezas englobadas en esta tipología se sitúa entre 29 y $76 \mathrm{~cm}$. Por la longitud de la parte metálica del ejemplar de L'Assut $(33 \mathrm{~cm})$, se debería incluir entre las de tamaño pequeño (18,5 a $40,5 \mathrm{~cm}$ ).

En el mismo estrato (UE 1306), se exhumó también un soliferreum (Fig. 8). Se trata de un arma arrojadiza de hierro de sección circular que apareció fragmentada, con una longitud total de 2,02 m, un diámetro aproximado de entre 1,5 y 2 $\mathrm{cm}$, y una punta de $4,5 \mathrm{~cm}$.

El soliferreum es una de las armas más características del armamento prerromano peninsular. Originaria del Lenguadoc/Aquitania, donde las hay desde la Primera Edad del Hierro, llegaría a la península ibérica en el siglo VI ANE, aumentando su presencia entre los siglos IV-II ANE, sobre todo en la zona levantina (Quesada, 1997). Tipológicamente se trata de un tipo de lanza fabricado por completo, punta y asta, en una sola pieza de hierro forjado, de aquí su nombre en latín. Siendo funcionalmente similar al pilum, la principal diferencia es su composición: el arma romana tiene una asta corta de madera y una larga espiga férrea terminada con una punta corta y maciza, mientras que el soliferreum es completamente metálico.

Se trata pues de un arma arrojadiza pesada, en la que predomina la capacidad de penetración en detrimento de otros efectos, como podría ser la anchura de la herida (Quesada, 1997), por lo tanto, la forma de la punta puede ser muy simple. Concretamente se pueden distinguir 6 tipos de punta, con o sin aletas, siendo las formas 1 y 5 las más sencillas. La otra característica utilizada para su clasificación es el tipo de enmangue. En el caso de L'Assut hay que indicar que el arma presenta un deterioro que no permite precisar si tendría algún tipo de moldura, pero todo indica que se trataría de una forma simple, del tipo A (empuñadura engrosada simple) o del tipo F (ligero engrosamiento del astil). Por lo tanto, proponemos para el ejemplar de L'Assut el tipo 5A (Quesada, 1993, 1997).

Conviene llamar la atención sobre la forma en la que apareció la pieza, doblada de un modo muy poco natural, en un único ángulo totalmente agudo más o menos en su mitad. Los soliferrea, habitualmente localizados en contextos funerarios, se inutilizan ceremonialmente doblándose en forma circular, ya sea para darles cabida en la tumba, o 


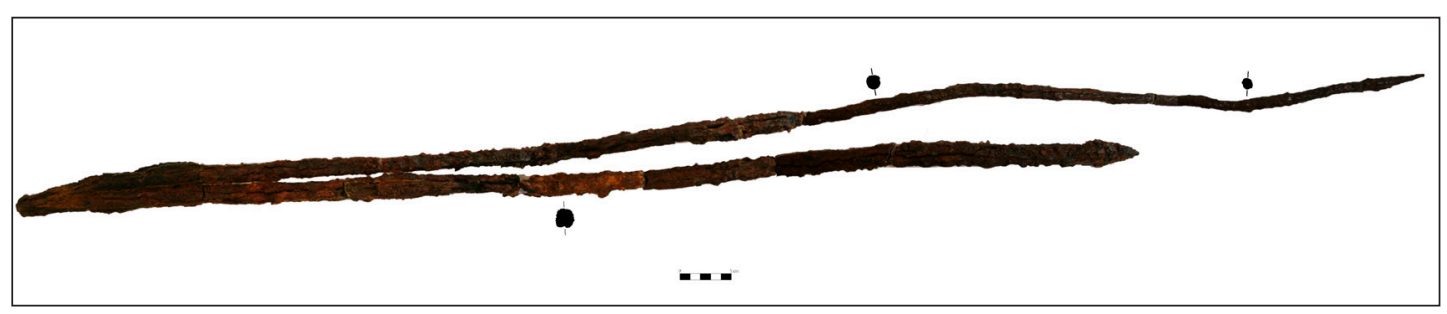

Figura 8. Soliferreum. GRESEPIA.

adoptando una ritualidad de destrucción asociada a la muerte de su propietario. Está claro que el contexto del soliferreum de L'Assut es muy diferente, y con los datos que tenemos únicamente podemos aventurar una inutilización funcional, forzada por las circunstancias en que fue incendiada la torre, o involuntaria, fruto del derrumbe de T3, aunque lamentablemente no se puede aportar más información es este sentido.

La cronología del arma, entre finales del siglo III e inicios del II ANE, la sitúan en un contexto plenamente relacionado con la información escrita más antigua sobre el uso de esta arma en Hispania «ut emissis soliferreis falaricisque gladios

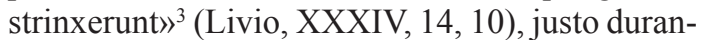
te la campaña de Catón en el noreste peninsular, el 195 ANE (Gener et alii, 2016: 24).

Otro elemento exhumado en la UE 1306 que podemos relacionar con las armas ofensivas, aunque sea indirectamente, es una placa de bronce fragmentada, con unas dimensiones de $8 \mathrm{~cm}$ de longitud, 5 de anchura y $0,1 \mathrm{~cm}$ de grosor, con una forma rectangular, rematada en un extremo por una lengüeta redondeada de $2,5 \mathrm{~cm}$ de longitud. No presenta ninguna decoración aparente, excepto un pequeño saliente, casi imperceptible, a lo largo del borde de todo el fragmento conservado (Fig. 9).

Con seguridad se trata de la parte proximal de una placa de la vaina de una espada de tipo La Tène, con unas medidas y forma que coinciden con los modelos habituales fabricados en el noreste peninsular, y que podríamos clasificar como una embocadura acampanada, tipo A2 de De Navarro, concretamente la variante 5 o la $\mathrm{B}$, acampanada de punta delgada (García Jiménez, 2012: 80). La ausencia de otros fragmentos nos hace plantear la posibilidad de que la vaina no estuviese hecha de una sola pieza de metal, sino que combinase

3 «Cuando, una vez arrojadas soliferrea y faláricas desenvainaron las espadas». diferentes materiales, entre ellos los orgánicos, y que estos pudieron haber desaparecido durante el incendio que asoló la torre. Si bien parece ser que en su origen el uso de materiales orgánicos en las vainas era habitual, estos se fueron sustituyendo por otros metálicos (García Jiménez, 2006: 126), que conllevaron a la existencia de vainas enterizas metálicas, aunque en la península ibérica se conservó el uso de materiales orgánicos, e incluso, con el paso del tiempo podía haberse dado de nuevo una «sustitución del hierro de las vainas por materiales orgánicos (madera o cuero), solo a veces reforzados por elementos metálicos» (García Jiménez, 2012: 137), como se constata en la Celtiberia. El uso de materiales orgánicos en vainas, preferido en el Mediterráneo, está perfectamente documentado en el noreste peninsular, como por ejemplo en Sant Julià de Ramis, donde a este tipo de vaina se le asocian unas anillas metálicas que actuarían como elementos de suspensión de la misma (García Jiménez, 2006: 141).

Sobre el fragmento de placa de vaina de L'Assut, cabe destacar también la excepcionalidad del material que la compone, el bronce, un metal que en estos elementos en origen se combinó con el hierro (por ejemplo, placa del anverso en bronce y del reverso en hierro), pero que con el paso del tiempo fue suplido por el hierro como metal único (García Jiménez, 2006: 126; 2012: 79), como hemos indicado. En este sentido una placa de bronce en la vaina es inusitada para esta época y esta región, aunque no desconocida en contextos galos de otras épocas.

Por último, queremos resaltar la presencia en T3 de varias anillas metálicas, que, si bien en un principio no se asociaron al armamento, una vez analizado el contexto en conjunto relacionamos con unos posibles elementos de suspensión de la vaina ${ }^{4}$. Se trata de tres anillas, una de bronce (con

${ }^{4}$ Queremos agradecer en este punto la ayuda inestimable de Gustavo García Jiménez en la identificación y clasificación 


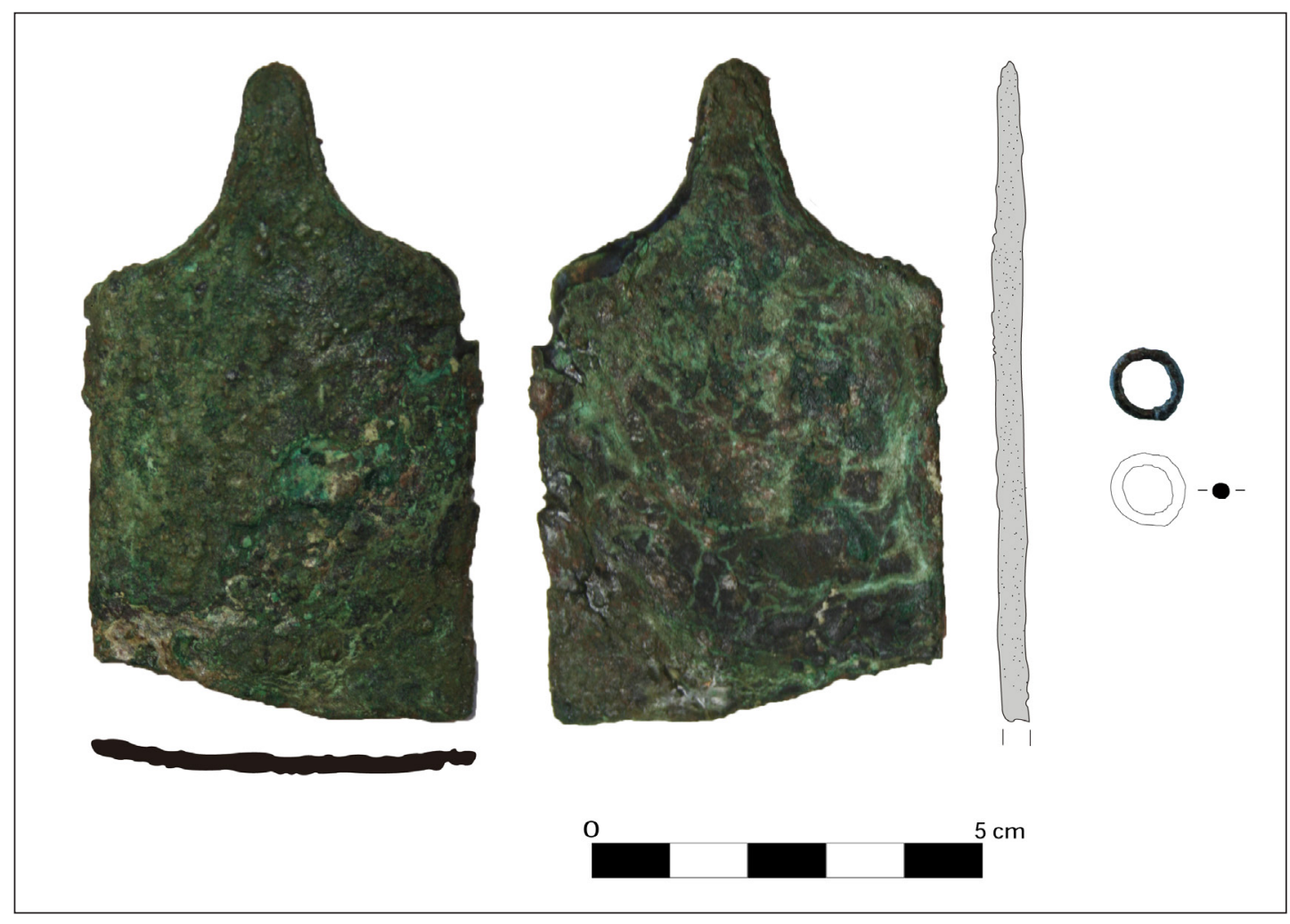

Figura 9. Fragmento de placa de bronce correspondiente a una vaina de espada tipo La Tène i anilla de bronce posiblemente asociada a la suspensión de la vaina. GRESEPIA.

un diámetro de $1 \mathrm{~cm}$ ) y dos de hierro, una de ellas fragmentada (con un diámetro de $5 \mathrm{~cm}$ ), que como hemos indicado podrían formar parte de la sujeción de la vaina mediante una correa colocada en tahalí o bandolera. En el nordeste peninsular hay paralelos de anillas de bronce y hierro asociadas a este tipo de armamento en contextos datados durante los siglos III y II ANE (García Jiménez, 2006: 148).

La recuperación de estas piezas indica indirectamente la presencia de una espada de tipo La Tène en la torre T3. Esta es un tipo de arma importada desde el área gala, pero que rápidamente fue imitada y producida en los talleres del noreste peninsular, generalizándose a partir de la Segunda Guerra Púnica (Quesada, 1997: 258). La vaina, como ya hemos indicado, posiblemente combinaría el metal con partes orgánicas desaparecidas durante el incendio, podría ser un distintivo del posible origen autóctono de la pieza (Quesada

del fragmento metálico de placa y su indicación sobre la funcionalidad de las anillas de bronce o hierro.
1997; 598), así como el sistema de anillas (Quesada, 1997: 252).

A nivel de clasificación, quizás resulta muy atrevido hacer una propuesta en ausencia del objeto, pero hay que señalar que las espadas de tipo La Tène se corresponden con la clase VII de Quesada, y más concretamente, la que no tienen vaina metálica entera, con sujeción mediante anillas, se englobarían en el tipo VIIC.

Por último, en la UE 1308, directamente asociada a la 1306 se recuperó un cuchillo afalcatado (Fig. 10), de unas dimensiones de $17 \mathrm{~cm}$ desde la punta superior de la hoja hasta la parte inferior del enmangue, $0,2 \mathrm{~cm}$ de sección y una anchura máxima de 2,2 cm. Este tipo de cuchillo está forjado a partir de láminas de hierro, generalmente golpeadas en frio para con posterioridad endurecer la hoja. La combinación del filo convexo y cóncavo le confiere un aspecto inconfundible. El elemento principal que lo diferencia de las falcatas es por supuesto el tamaño y la ausencia de filo dorsal, indicando que los cuchillos servían más para cortar que para pinchar. 
En cuanto a su función, existe cierta controversia sobre su adscripción a la categoría de armas, como propusieron en su momento Kurtz Schaefer (1986-1987: 456) o Lorrio (1993: 312), o a la de instrumentos asociados a la ritualidad. Almagro Gorbea y Lorrio, en un interesante trabajo, revisan su función o uso en distintos espacios, tanto sacrificiales como armamentísticos, indicando su valor simbólico en la panoplia hispana (Almagro Gorbea, Lorrio, 2010). Quesada opina que podría ser un ítem propio de la ritualidad sacrificial, como pervivencia de épocas anteriores, si bien apunta que, a partir del siglo V ANE, los cuchillos afalcatados se asocian a ajuares funerarios de armas, amortizados como ofrendas (Quesada, 1997: 167-168). La iconografía muestra la asociación del guerrero con espada y cuchillo, mostrando en las vainas de las espadas un compartimento para colocar el cuchillo, como se reproduce en el "Guerrero de Porcuna" (Quesada, 1997) o en el "Guerrero sacrificante", de forma que para algunos autores la presencia de este elemento simbolizaría «el estatus del aristócrata gentilicio como sacerdote oficiante de los ritos sacrificiales a los antepasados» (Almagro Gorbea y Lorrio, 2010: 162).

La percepción ritual ha estado refrendada así mismo por otros autores. Mateos y Sánchez indican que en el área vetona hay un patrón común para todas las armas ofensivas prerromanas, y es que están hechas para pinchar, mientras que el cuchillo afalcatado tiene un filo único, cóncavoconvexo, de forma que se trata de un elemento de corte (Mateos y Sánchez, 2014: 145). Si bien esto no excluye su posible uso como arma ofensiva dentro de la panoplia ibérica, abre el camino a buscarle otras interpretaciones, como por ejemplo su vinculación a los sacrificios ceremoniales asociados al mundo funerario o a otras ritualidades (Olmos, 2000). Por lo tanto, la función estricta de estos elementos no está clara, siendo plausible una multifuncionalidad no restrictiva que incluiría todas las opciones: arma dentro de la panoplia guerrera, una herramienta de corte, relacionada o no con la ritualidad, o ambos usos.

Para finalizar, en los mismos niveles en que apareció el conjunto armamentístico, se localizaron algunos fragmentos de hierro y bronce de difícil adscripción, que, si bien podrían asociarse a la presencia de un escudo, su estado de conservación nos demanda cierta cautela. A pesar de ello, podemos apuntar que la presencia de un escudo acompañando el conjunto descrito es prácticamente

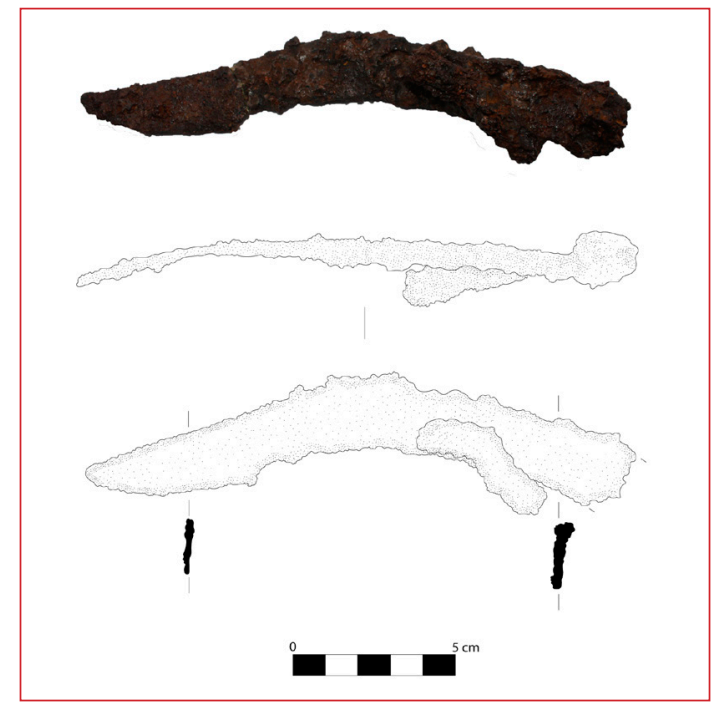

Figura 10. Cuchillo afalcatado. GRESEPIA.

incuestionable, pues fue por excelencia el arma defensiva más utilizada por los pueblos prerromanos de la península ibérica. Fácil de fabricar, de bajo coste, estaba al alcance de cualquier guerrero y tenía un carácter insustituible y activo, diferente al resto del armamento defensivo (Quesada, 1997: 483). En el noreste peninsular, desde mediados del siglo III ANE el escudo por excelencia es de tipo oval, en asociación a otros elementos de la panoplia celta (Quesada, 1997; 2003). Construidos mediante madera, cuero $u$ otros materiales orgánicos, solo el umbo, la manilla, la orla o la spina longitudinal serían elementos perdurables en contextos arqueológicos, por su constitución metálica. Aun así, no todos tenían el umbo o manilla metálicos, de forma que muchas veces, las únicas piezas imperecederas o reconocibles son los clavos de hierro de sujeción (Núñez y Quesada, 2000), hecho que dificulta en fuerte medida su identificación (García Jiménez, 2011: 428)5 . Es interesante recalcar que, en el área catalana, la presencia de escudos se limita a las necrópolis, mientras que en territorio valenciano y en el sur, donde aparecen profusamente en la iconografía, sin el esbozo de la spina, el umbo metálico, y en ocasiones sin manilla, sustituida por otros siste-

5 «No hay que olvidar que muchos (quizás la mayoría) de los escudos ovales peninsulares debieron fabricarse enteramente a partir de materiales lignarios y otros compuestos orgánicos y nunca se acompañaron de umbos metálicos» (García Jiménez, 2011: 449). 
mas de sujeción (Quesada, 2003: 80), su localización material es inexistente, hecho que quizás pudiera explicarse por su naturaleza perecedera.

Vistos los datos presentados, estamos en situación de confirmar la existencia en la torre T3 de L'Assut de una panoplia ofensiva ibérica completa, correspondiente a finales del Ibérico Pleno. Ya hemos indicado que el conjunto de armas de un guerrero ibérico poseía o utilizaba en combate varió/evolucionó a lo largo de los años. Además, el tipo de armamento imperante también obedecía a otros factores: la tradición, las influencias foráneas, el carácter artesanal de la producción, las adaptaciones a necesidades específicas o las imitaciones, unas variables que acabarían conformando el conjunto. La panoplia ofensiva de época avanzada o "panoplia simplificada" —230 a 100 ANE- (Quesada, 1997; 2002), en uso en el momento de destrucción de T3, estaría compuesta por una espada La Tène o tipo La Tène (entendida esta como una producción local), una lanza y una jabalina (Quesada, 1997: 619). Este es el conjunto recuperado en T3, y todavía hay que añadirle el soliferreum, como arma arrojadiza pesada, la posible "falárica" y el cuchillo afalcatado. Un lote impresionante, con unos rasgos fuertemente "celtizantes", que seguramente estaría completado por una panoplia defensiva de la que no nos ha quedado un rastro suficientemente tangible.

\section{INTERPRETACIÓN DEL CONJUNTO}

El estudio de conjuntos armamentísticos procedentes de espacios de hábitat no es habitual para la época ibérica, como ya hemos indicado anteriormente. Hay que relacionar este tipo de hallazgos siempre con sucesos violentos, que implican destrucción y pérdida, o actividades rituales, que indican una deposición voluntaria. En el primero de los casos, la inmediatez e imprevisión del suceso nos muestra el conjunto tal y como era, sin excesivas manipulaciones o en el caso de que las hubiese, siempre relacionadas con el interés material de la apropiación (botín) o de la eliminación, por lo tanto, una disminución del lote interpretable. Por eso el conjunto de L'Assut, con las características inherentes a su conservación y hallazgo, es una muy buena representación de la panoplia ofensiva de un guerrero ibérico de finales del siglo III ANE: dos armas específicamente arrojadizas, la falárica y el soliferreum, y una lanza, arma ibérica por excelencia (Quesada, 1997: 421), básica en la lucha cuerpo a cuerpo, ya que, en su momento de uso, una vez arrojadas las primeras, el combate se entablaría con esta (Quesada, 1997: 433) ${ }^{6}$. Piezas eminentemente de guerra, acompañadas de un cuchillo afalcatado y la más que probable presencia de una espada tipo La Tène. La ausencia indirecta de material defensivo se podría interpretar perfectamente por el carácter perecedero de la materia prima básica — cuero o madera- que conformaría corazas o escudos, siendo las partes metálicas (en el caso del escudo el umbo, las manillas o los clavos de sujeción), las únicas conservables, que, en caso de existir, podrían estar perfectamente camufladas entre el conjunto metálico indeterminado recuperado en $\mathrm{T} 3$.

Hoy en día, el estudio de las armas nos aporta una ingente cantidad de datos que sobrepasa en gran medida su peso material: procesos tecnológicos, sociedad, política, economía, género, ritualidad, creencias, simbolismo y otros parámetros, que en combinación con una lectura profunda de las fuentes grecolatinas que se refieren a ellas, son claves para conocer y explicar la cultura ibérica, aportando nuevas perspectivas, esenciales para su comprensión. De este modo, en los estudios sobre esta sociedad, se ha insistido habitualmente en la mentalidad guerrera de sus componentes, así como en la relación entre los hombres libres y su armamento. Esta afinidad se puede contrastar tanto a nivel arqueológico como literario. Solo hace falta recordar en este aspecto a Pompeo Trogo, a través de Justino, describiendo el apego de los pueblos prerromanos peninsulares a sus armas: «arma sanguine ipsorum cariora» ${ }^{7}(44,2,5)$. Polibio, Livio, Apiano, Diodoro o Plutarco confirman esta íntima relación entre iberos y celtiberos y su armamento, destacando, por lo cercano de los hechos, el pasaje en que Livio se refiere a la negativa de los bergistanos, enfrentados y vencidos por Catón, a desarmarse (Livio, XXXIV, 17). Y no es únicamente por el valor económico de los objetos, sino también por su valor simbólico, su significado sociopolítico; una afirmación que nos lleva a preguntar: entre los íberos ¿quién llevaba armas? Es evidente que la posesión de un tipo determinado de armas debería tener un significado social y posiblemente político.

\footnotetext{
${ }^{6}$ De hecho, la lanza fue la principal arma ofensiva de la Antigüedad, y así aparece representada literal y materialmente (Quesada, 1997: 431).

7 «Las armas les eran más queridas que la propia vida».
} 
En primer lugar, estamos totalmente de acuerdo con los autores que afirman que las armas son una distinción del individuo libre, tal y como se expresa en todo el Mediterráneo durante la Edad Antigua (Quesada, 2010). No hay armas para los sometidos, tengan la categoría que tengan, ya que el primer paso para exponer esta sumisión es el desposeimiento de todo tipo de armas.

En segundo lugar, y aquí queremos delinear una pequeña divergencia, muy posiblemente las panoplias completas pertenecerían a los grupos más favorecidos de la comunidad, unas élites que ostentarían o participarían del poder y/o de las decisiones políticas de su colectivo. Solo hace falta recordar la importancia y valor del armamento y su interrelación con las diferentes clases sociales griegas o romanas, base organizativa de sus respectivos ejércitos. Qué duda cabe que el valor de las armas expresa también este papel político preeminente, como se desprende de la magnificencia de algunas de las armas inhabilitadas en ajuares funerarios, símbolos de la importancia personal o del linaje del difunto, o, aunque no sea tan frecuente, la presencia de armas en tumbas femeninas, como emblema de prestigio.

Tanto la destrucción de la torre T3 de L'Assut, como la presencia de las armas que hemos descrito, nos remiten a una interpretación de este espacio como la residencia de un personaje distinguido, que tendría alguna preeminencia sobre el resto de los habitantes del poblado. Este hecho se manifestaría a través del lugar elegido para vivir, así como por sus posesiones, armas y objetos productivos, entre otros ${ }^{8}$. Seguramente esta posición social fue clave para la acción romana que culminó con el incendio de T3: la destrucción de los símbolos, el incendio y desolación de una vivienda distintiva, juntamente con la aniquilación de las posesiones más preciadas de su propietario, como el armamento, así como la prohibición de recuperarlo, tenían que servir para subrayar el poder de los conquistadores.

Pierre Guérin, a raíz de los trabajos llevados a cabo en el Castellet de Bernabé (Guérin, 2003), en el contexto de destrucción del poblado, planteaba una posible segregación espacial interna de un espacio arquitectónico diferencial, desde un punto de vista social a la vez que de género, a partir del

\footnotetext{
${ }^{8}$ Entre estos podemos destacar elementos de ornamentación personal, materiales exógenos (corcho) o cerámicas y productos de importación.
}

descubrimiento de un conjunto armamentístico y de un lote de herramientas agrícolas, detallando que las armas y los medios de producción estarían controlados por una élite familiar, donde la mujer sería la encargada de organizar la producción, mientras que los hombres de rango del mismo núcleo sanguíneo desarrollarían un papel militar, y el resto de habitantes, de una categoría social inferior, soportarían un estado servil (Guérin, 2003: 336-337). Esta interpretación se apoyaba también en los contrastes arquitectónicos del lugar ocupado por esta élite, un espacio separado del resto mediante un muro, con una superficie que supondría el $20 \%$ del total del yacimiento. Guérin expresaba el instante de la destrucción como «el momento de maduración del proceso por el cual la aristocracia separó definitivamente la estructura clientelar de las relaciones de parentesco, que quizás podrían haber articulado la comunidad desde su inicio hasta ese momento» (Guérin, 2003: 338), una visión que ha sido respaldada por otros investigadores, como Arturo Ruiz Rodríguez, quien vería en ello la máxima expresión de un modelo social clientelar, en el cual las aristocracias controlarían tanto los aspectos productivos como la posesión de las armas y los productos importados (Ruiz Rodríguez, 1998: 295).

En todo caso, una formulación que también ha suscitado discrepancias, sobre todo respecto a su contenido fundamental, que no es otro que la posesión de las armas. Fernando Quesada, en un brillante artículo, indica muy claramente que la documentación literaria o arqueológica aporta numerosos ejemplos de la asociación del armamento con el individuo y en particular con el concepto de libertad personal, percibiéndose las armas como un emblema de esta libertad (Quesada, 2010: 19), de forma que no se debería vincular esta posesión únicamente con una elite aristocrática, sino con este estatus de "hombre libre" (Quesada, 2010: 21). De hecho, y muy diáfanamente, explora la dispersión de las armas en una muestra de asentamientos (donde no existe la carga ritual de las necrópolis), para concluir que si bien estos parámetros expresados por Guérin o Ruiz Rodríguez podrían aplicarse a momentos antiguos de la cultura ibérica (incluyendo los formativos), hacia el 200 ANE la propiedad de las armas se correspondería básicamente con el estamento de los hombres libres, hasta el punto de identificarlos como tales (Quesada, 2010: 37).

Un estudio efectuado entre armas y sociedad en época ibérica en la Laietania, en el nordeste 
peninsular, expresa un punto intermedio entre estos planteamientos, esbozando como hipótesis la existencia de unas armas reservadas solo a algunos personajes de rango (casco o falcata), mientas que la abundancia de otros tipos, como las espadas tipo La Tène o los escudos, se asociarían directamente con un colectivo especializado, los guerreros o personas hábiles en su uso (García Rosselló et alii, 1998: 323), un grupo formado por personas libres que ostentarían el poder, basado sobre todo en la destreza y seguramente también en la propia posesión del armamento. El mismo grupo dirigente que se enterraría en cementerios selectivos (García Rosselló et alii, 1998: 324).

En nuestro caso pensamos que seguramente las armas, en un momento anterior al Ibérico Pleno, tendrían un significado sociopolítico trascendental, pues se asociarían a la emergencia de una aristocracia guerrera que se habría erigido dueña y señora del territorio, apropiándose de símbolos y rituales y ocupando unos espacios arquitectónicos segregados, las casas fortificadas, así como de un ceremonial funerario diferencial, manifestado de manera habitual mediante la riqueza de unos ajuares abundantes en armas (Diloli, 2018). Este panorama cambiaría a partir de mediados y sobre todo durante el último cuarto del siglo V ANE, con la desestructuración y desaparición de este sistema, sustituido por un nuevo orden sustentado en un aumento demográfico, que supondría la fundación de nuevos asentamientos organizados distintamente, así como con un abandono de las necrópolis, o mejor dicho de la ritualidad asociada a las mismas hasta el momento, con contadas excepciones. Una transformación que no aporta ningún elemento arqueológico que permita defender la pervivencia de un poder aristocrático como el imperante en la época inmediatamente anterior.

Con todo, el modelo que plantea Pierre Guerín y apoya Arturo Ruiz Rodríguez, resulta seductor para L'Assut, ya que hay una alta coincidencia entre los datos del Castellet de Bernabé y los que observamos en L'Assut: existencia y pervivencia de un espacio diferencial, distintivo, aislado del resto - la torre T3 - (¿quizás incluso impregnado de una memoria/imagen de linaje?), que seguramente habría estado ocupada por un personaje de peso en el marco de la comunidad, como lo demuestra la existencia de esta panoplia entera (y hasta aumentada) de guerrero, la presencia del cuchillo afalcatado (simbología ritual), así como de los elementos de producción (herramientas agrícolas relacionadas con el cultivo de la vid, entre otros), un asador y una parrilla (elementos vinculados a los banquetes diferenciales), que también podrían representar un estatus privilegiado, o la existencia constatada de uno o varios telares en el piso superior de la torre, un tipo de elemento/ función simbólicamente ligado a las mujeres de rango (Guérin, 2003: 334).

En todo caso, estamos hablando de un poblado que en el momento de la destrucción de T3 ocuparía casi media hectárea de extensión, por lo tanto, con un volumen considerable de viviendas y de población, siendo los restos del interior de la torre los que corresponden únicamente a una sola persona/familia, no a toda la comunidad. Así pues, partimos de un registro sesgado, ya que la destrucción solo afectó a un edificio, que, simbólico o no, es el único que nos ha proporcionado datos sobre este momento concreto de su existencia. Por lo tanto, desconocemos si este modelo se repetiría o no en otros edificios del poblado durante la misma época. Esto nos impide definir, como en el caso del Castellet de Bernabé, una "casa del aristócrata". Lo único que podemos afirmar con rotundidad es que, con los datos actuales sobre la cultura ibérica del noreste, tanto el edificio, su contenido, como el momento y forma de destrucción, muestran con seguridad un estatus diferencial para el mismo y para sus ocupantes.

No podemos ir más allá en esta discusión, pero sí queremos hacer notar de nuevo la relevancia de los datos para intentar reconstruir la secuencia histórica en la que se produjeron los hechos que hemos narrado hasta ahora. Es obvio, y ya se ha repetido muchas veces, que no se debe caer en la tentación de asociar hechos históricos facilitados por los textos clásicos con hallazgos arqueológicos que no sean del todo patentes, pero creemos que con la investigación efectuada los últimos años, esta proclama ha quedado en buena parte desfasada. El descubrimiento de espacios históricos citados en los textos clásicos, como por ejemplo campamentos, campos de batalla, movimientos de tropas u otros sucesos bélicos, ha generado un nuevo ámbito de estudio que ha proporcionado importantes avances en el conocimiento de la Edad Antigua de la península ibérica (Bellón et alii, 2015; Noguera 2008, 2012; Noguera et alii, 2012, 2014). Así, en el noreste peninsular, las destrucciones o afectaciones a yacimientos indígenas entre finales del siglo III e inicios del II ANE se han asociado tradicionalmente a dos hechos históricos de primer orden: la Segunda Guerra Púnica y los posteriores levantamientos de las comunida- 
des ibéricas contra la presencia romana, siendo las primeras la revuelta de los ilergetas y sus aliados (206-205 ANE), seguramente las más cercanas a la zona del río Ebro. Asimismo, la revuelta generalizada de los íberos del norte durante los años siguientes y la posterior represión efectuada por Catón ha sido un tema ampliamente tratado por la historiografía. El hecho, documentado por el propio cónsul, lo transmite Livio, especificando cómo después de una rápida campaña el general romano ya había sometido a diversos pueblos ibéricos del noreste de la península (Livio, XXXIV, $20,1)$. También nos relata como el militar romano ideó una estratagema para desarmar a los pueblos ibéricos con el mínimo desgaste (Livio, XXXIV, 17), un engaño que, cierto o no, tenía que posibilitar la eliminación de los sistemas defensivos de los poblados ibéricos de la región. Aunque no podemos confirmar con total certeza si la maniobra se aplicó, sí que parece que durante este mismo periodo se produjeron importantes destrucciones en algunos asentamientos indígenas tanto del territorio del Ebro (Noguera et alii, 2012, 2014), como del resto del área catalana (Sanmartí y Santacana, 2005: 185). El caso de T3, responde a estos parámetros tanto a nivel cronológico como por el simbolismo de la destrucción, de forma que no podemos desestimar su relación, al menos a prio$r i$, con los procesos históricos acontecidos en este momento en el noreste peninsular.

En palabras de Muñiz y Quesada para otro momento y contexto, pero con los mismos protagonistas:

una destrucción tan completa seguida de abandono es 'marca de la casa' de la acción de Roma cuando sus enemigos no se sometían sin condiciones. Venganza, represalia, política fríamente decidida pour encourager les autres..., no podemos saberlo todavía. Pero la romanización no fue siempre un proceso pacífico, consensuado y aceptado por todas las partes. Muy al contrario, fue traumático y a menudo extremadamente violento (Muñiz y Quesada, 2010: 94).

\section{BIBLIOGRAFÍA}

Almagro Gorbea, M. y Lorrio, A. J. (2010): «El “Heros Ktistes" y los símbolos de poder de la Hispania prerromana», F. Burillo Mozota (coord.), Ritos y mitos: VI Simposio sobre Celtiberos. Mara, Centro de Estudios Celtibéricos de Segeda: 157-181.

Bea, D. (2012): Poder, arquitectura i complexitat social. Formes politiques al curs inferior de l'Ebre durant la protohistòria. Tesis doctoral. Universitat Rovira i Virgili. Tarragona. https://www.tesisenred. net/handle/10803/84029\#page=1.

Bea, D.; Diloli, J.; Garcia, D.; Moreno, I. y Moret, P. (2012): «Arquitectura de prestigio y aristocracias indígenas», C. Belarte, J. A. Benavente, L. Fatás, J. Diloli, P. Moret y J. Noguera (eds.), Iberos del Ebro, Actas del II Congreso Internacional. Serie Documenta, 25. Tarragona, ICAC: 51-70.

Bellón, J. P.; Ruiz, A.; Molinos, M.; Rueda, C. y Gómez, F. (eds.) (2015): La Segunda Guerra Púnica en la península ibérica. Baecula: arqueología de una batalla. Jaén, Publicaciones de la Universidad de Jaén.

Diloli, J. (2009): «La perduración del poder en un espacio arquitectónico simbólico. La torre T-3 del asentamiento protohistórico de L'Assut (Tivenys, Baix Ebre, Tarragona)». Trabajos de Prehistoria, 66, núm. 2: 119-142. https://doi.org/10.3989/ tp.2009.09023

Diloli, J. (2018): «Comerç, poder, aristocràcia. La formació del món ibèric a les Terres de l'Ebre». Miscel-lània del CERE, 28: 179-202.

Diloli, J.; Ferré, R.; Vilà, J.; Cots, I.; Bricio, L.; Prades, M. y Bea, D. (en prensa): «Relaciones entre indígenas y fenicios en el curso inferior del Ebro. La primera fase de ocupación del asentamiento protohistórico de L'Assut (Tivenys, Baix Ebre, Tarragona) y su integración en el territorio». IX Congreso Internacional de Estudios Fenicios y Púnicos (Mérida, 22 a 26 de octubre de 2018). MYTRA, 5.

Farnié, C. y Quesada, F. (2005): Espadas de hierro, grebas de bronce. Símbolos de poder e instrumentos de guerra a comienzos de la Edad del Hierro en la Península Ibérica. Serie Monografías del Museo de Arte Ibérico de El Cigarralero, 2. Murcia.

García Jiménez, G. (2006): Entre iberos y celtas: las espadas de tipo La Tène del noreste de la Península Ibérica. Anejos de Gladius, 10. Madrid, CSIC.

García Jiménez, G. (2011): El armamento de influencia La Tène en la Península Ibérica (siglos V-I a.C.). Tesis Doctoral. Universitat de Girona. Girona. https://www.tdx.cat/handle/10803/51613\#page=1

García Jiménez, G. (2012): El armamento de influencia La Tène en la Península Ibérica (siglos V-I a.C.). Monographies Instrumentum, 43. Montagnac.

García Roselló, J.; Zamora, M. y Pujol, J. (1998): «Armament i societat a la Laietània ibérica», Congreso internacional: Los iberos Príncipes de occidente. Estructuras de poder en la sociedad ibérica (Barcelona, marzo de 1998). Saguntum, Extra-1. Valencia, Universitat de València: 309-325.

Gener, M.; Romero, D.; González, S. y García, J. (2016): «Estudio metalúrgico de las armas ibéricas halladas en el valle de Jutia (Nerpio-Yeste, Albacete). Trabajo, armamento, ritual y comunidades de montaña». Gladius, XXXVI: 7-31. https://doi. org/10.3989/gladius.2016.0001 
Guérin, P. (2003): El Castellet de Bernabé y el horizonte ibérico pleno edetano. Serie de Trabajos Varios, 101. València, Museu de Prehistòria de València.

Kurtz Schaefer, G. (1986-1987): «El armamento en la necrópolis de las Cogotas (Cardeñosa, Ávila)». Zephyrus, 39-40: 445-458.

Lorrio, A. J. (1993): «El armamento de los celtas hispanos», M. Almagro y G. Ruiz (eds.), Los Celtas: Hispania y Europa. Madrid, Editorial Actas: 285326.

Mateos, C. M. y Sánchez, D. (2014): «El cuchillo afalcatado. Análisis tipológico y funcional de los cuchillos de los yacimientos Abulenses durante la II Edad del Hierro», F. J. González de la Fuente, E. Paniagua Vara y P. de Inés Sutil (coord.), Investigaciones arqueológicas en el valle del Duero. Del Paleolítico a la Antigüedad Tardía: actas de las III Jornadas de Jóvenes Investigadores del Valle del Duero (Salamanca, noviembre de 2013), Valladolid, Glyphos, vol. 3: 135-150.

Moret, P. (2002): «Tossal Montañés y La Gessera: ¿residencias aristocráticas del Ibérico Antiguo en la cuenca media del Matarraña?», I Jornades d'Arqueologia. Ibers a l'Ebre. Recerca i interpretació. Ilercavònia. Fulls d'Arqueologia, 3. Flix, Centre d'Estudis de la Ribera d'Ebre: 65-73.

Moret, P.; Benavente, J. A. y Gorgues, A. (2006): Iberos del Matarraña. Investigaciones arqueológicas en Valdeltormo, Calaceite, Cretas y La Fresneda (Teruel). Āl-Qannīš. Boletín del Taller de Arqueología de Alcañiz, 11. Alcañiz.

Moret, P. y Chapa, T. (eds.) (2004): Torres, atalayas y casas fortificadas. Explotación y control del territorio en Hispania (S. III a de C - S. I d. de C). Jaén, Universidad de Jaén.

Muñiz, I. y Quesada, F. (2010): Un drama en tres actos. Dos milenios de ocupación humana en el Cerro de la Cruz (Almedinilla, Córdoba). Oikos, 2. Cuadernos Monográficos del Ecomuseo del Río Caicena. Almedinilla.

Noguera, J. (2008): «Los inicios de la conquista romana en Iberia. Los campamentos de campaña del curso inferior del río Ebro». Archivo Español de Arqueología, 81: 31-48. https://doi.org/10.3989/ aespa.2008.v81.39

Noguera, J. (2012): «La Palma-Nova classis. A Publius Cornelius Scipio Africanus encampment during the Second Punic War in Iberia». Madrider Mitteilungen, 53: 262-288.

Noguera, J.; Asensio, D.; Ble, E. y Jornet, R. (2014): «The beginnings of the Roman conquest of Hispania. Archaeological evidence of the assault and destruction of the Iberian city of Castellet de Banyoles (Tivissa, Tarragona)». Journal of Roman Archaelogy, 27: 60-81. https://doi.org/10.1017/ s1047759414001160

Noguera, J.; Asensio, D. y Jornet, R. (2012): «La destrucción del Castellet de Banyoles (Tivissa, Ta- rragona)», Iberos del Ebro, Actas del II Congreso Internacional. Serie Documenta, 25. Tarragona, ICAC: 231-246.

Núñez, E. y Quesada, F. (2000): «Una sepultura con armas de baja época ibérica (o época romana republicana), en la necrópolis del Cerro de las Balas (Écija, Sevilla)». Gladius XX: 192-220. https://doi. org/10.3989/gladius.2000.70

Olmos, R. (2000): «La sociedad ibérica a través de la imagen». Los iberos y sus imágenes. Madrid, Micronet-CSIC, ed. cdrom, $n^{\circ} 85.2$.

Pérez Daza, F. (2003): «Nueva aportación al estudio del armamento ibérico en la línea Almedinilla-Porcuna-Andújar». Antiquitas, 15: 59-64.

Quesada, F. (1992): Arma y símbolo. La falcata ibérica. Alicante, Instituto Juan Gil-Albert.

Quesada, F. (1993): «Soliferrea de la Edad del Hierro en la Península Ibérica». Trabajos de Prehistoria, 50: 159-183. https://doi.org/10.3989/tp.1993.v50. i0.495

Quesada, F. (1997): El armamento ibérico. Estudio tipológico, geográfico, funcional, social y simbólico de las armas en la Cultura Ibérica (siglos VI-I a.C.). Monographies Instrumentum, 3. Montagnac, Monique Mergoil.

Quesada, F. (1998): «Aristócratas a caballo y la existencia de una verdadera "caballería" en la cultura ibérica: dos ámbitos conceptuales diferentes», C. Aranegui (ed.), Los Iberos, principes de Occidente. Actas del Congreso Internacional (Barcelona, marzo de 1998). Saguntum, Extra-1. Valencia, Universitat de València: 169-183.

Quesada, F. (2002): «La evolución de la panoplia, modos de combate y tácticas de los iberos», P. Moret y F. Quesada (eds.), La guerra en el mundo ibérico y celtibérico (ss. VI-II a. de C.). Seminario celebrado en la Casa de Velázquez (marzo de 1996). Madrid, Casa de Velázquez: 35-64.

Quesada, F. (2003): «La guerra en las comunidades ibéricas (c. 237-c. 195 a.C.): un modelo interpretativo», A. Morillo, F. Cadiou y D. Hourcade (eds.), Defensa y territorio en Hispania de los Escipiones a Augusto. León-Madrid, Universidad de León y Casa de Velázquez: 101-156.

Quesada, F. (2005): «El guerrero ibérico a través de El Cigarralejo», El Museo de Arte Ibérico de El Cigarralejo. Murcia, Dirección General de Cultura: 111-134.

Quesada, F. (2006): «Armamento indígena y romano republicano en Iberia (siglos III-I a.C.): compatibilidad y abastecimiento de las legiones republicanas en campaña», A. Morillo (ed.), Arqueología militar romana en Hispania. Producción y abastecimiento en el ámbito militar. León, Universidad de León: $75-96$.

Quesada, F. (2007): «Hispania y el ejército romano republicano. Interacción y adopción de tipus metáli- 
cos». Sautuola: Revista del Instituto de Prehistoria y Arqueología, 13: 379-402.

Quesada, F. (2009): «La guerra en la Cultura Ibérica», M. Almagro (coord.), Historia militar de España. Prehistoria y Antigüedad. Madrid, Ministerio de Defensa: 111-130.

Quesada, F. (2010): «Las armas en los poblados ibéricos: teoría, método y resultados». Gladius, XXX: 17-42. https://doi.org/10.3989/gladius.2010.0001

Quesada, F. (2011a): «El armamento en un poblado ibérico del siglo IV a.C. Una oportunidad excepcional», H. Bonet Rosado y J. Vives-Ferrándiz Sánchez (eds.): La Bastida de les Alcusses. 19282010. Valencia, Museu de Prehistòria de València: 197-219.

Quesada, F. (2011b): «Amaban sus armas más que a la propia vida. Los antiguos iberos y su panoplia bélica». Andalucía en la Historia, 32: 20-25.

Rovira, M. C. (1994): «Agricultura i desenvolupament tecnològic a la protohistòria: la introducció del fe- rro», J. M. Fullola, J. Juan y M. A. Petit (eds.), $P a-$ leoetnobotànica aplicada a l'arqueologia prehistòrica. Barcelona, Societat Catalana d'Arqueologia: 141-156.

Ruiz Rodríguez, A. (1998): «Los príncipes iberos: procesos económicos y sociales», Actas del Congreso Internacional Los Iberos, Príncipes de Occidente (Barcelona, marzo de 1998). Saguntum, Extra-1. Valencia, Universitat de València: 289-300.

Sanmartí, J. y Santacana, J. (2005): Els ibers del nord. Barcelona, Rafael Dalmau Editor.

Schulten, A. (1943): «Pilum», R. E. Pauly-Wissowa. Stuttgart, J. B. Metzler: 1333-1370.

Vives-Ferrándiz, J.; Bonet, H.; Carrión, Y.; Ferrer, C.; Iborra, P.; Pérez, G.; Quesada, F. y Tortajada, G. (2015): «Ofrendas para una entrada: un depósito ritual en la Puerta Oeste de la Bastida de les Alcusses (Moixent, Valencia)». Trabajos de Prehistoria, 72, 2: 282-302. https://doi.org/10.3989/tp.2015.12155 
